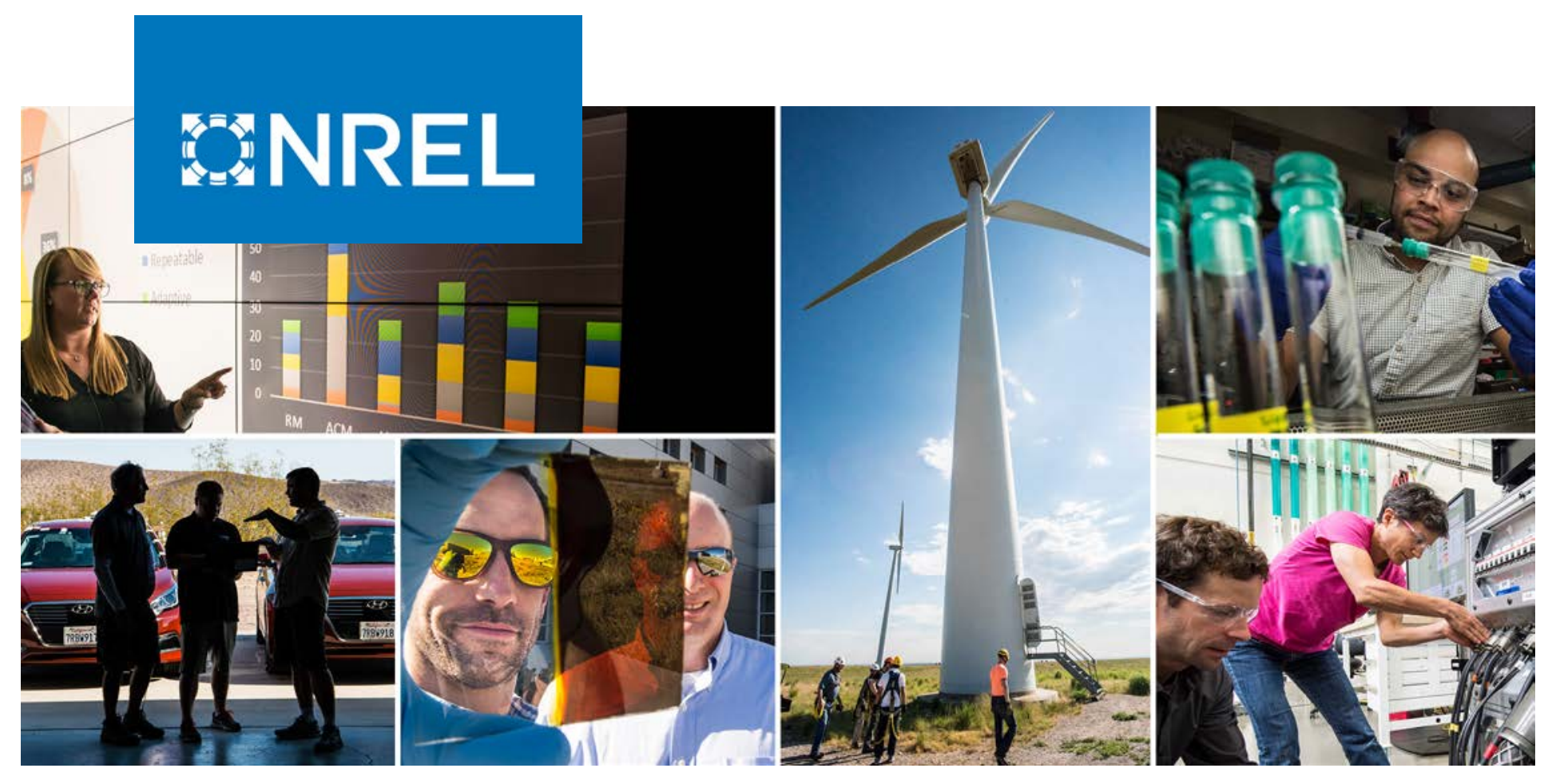

\title{
Iquitos Solar Energy Integration Study
}

Carlo Brancucci, ${ }^{1}$ James McCall, ${ }^{2}$ Owen Zinaman, ${ }^{2}$ Hugo N. Villegas Pico, ${ }^{2}$ and Vahan Gevorgian ${ }^{2}$

1 encoord, LLC

2 National Renewable Energy Laboratory

NREL is a national laboratory of the U.S. Department of Energy Office of Energy Efficiency \& Renewable Energy

Operated by the Alliance for Sustainable Energy, LLC

This report is available at no cost from the National Renewable Energy Laboratory (NREL) at www.nrel.gov/publications.

\section{Technical Report}

NREL/TP-5D00-73675

March 2020 


\section{GNREL}

\section{Iquitos Solar Energy Integration Study}

Carlo Brancucci, ${ }^{1}$ James McCall, ${ }^{2}$ Owen Zinaman, ${ }^{2}$ Hugo N. Villegas Pico, ${ }^{2}$ and Vahan Gevorgian ${ }^{2}$

1 encoord, LLC

2 National Renewable Energy Laboratory

\section{Suggested Citation}

Brancucci, Carlos, James McCall, Owen Zinaman, Hugo N. Villegas Pico, and Vahan Gevorgian. 2020. Iquitos Solar Energy Integration Study. Golden, CO: National

Renewable Energy Laboratory. NREL/TP-5D00-73675.

https://www.nrel.gov/docs/fy20osti/73675.pdf.

NREL is a national laboratory of the U.S. Department of Energy Office of Energy Efficiency \& Renewable Energy Operated by the Alliance for Sustainable Energy, LLC

This report is available at no cost from the National Renewable Energy Laboratory (NREL) at www.nrel.gov/publications.

Contract No. DE-AC36-08GO28308
Technical Report NREL/TP-5D00-73675 March 2020

National Renewable Energy Laboratory 15013 Denver West Parkway Golden, CO 80401 303-275-3000 • www.nrel.gov 


\section{NOTICE}

This work was authored by the National Renewable Energy Laboratory, operated by Alliance for Sustainable Energy, LLC, for the U.S. Department of Energy (DOE) under Contract No. DE-AC36-08GO28308. Funding provided by the Hewlett Foundation, the U.S. State Department, and the U.S. Agency for International Development (USAID) under the Leadership Compact Program. The views expressed herein do not necessarily represent the views of the DOE or the U.S. Government.

This report is available at no cost from the National Renewable Energy Laboratory (NREL) at www.nrel.gov/publications.

U.S. Department of Energy (DOE) reports produced after 1991 and a growing number of pre-1991 documents are available free via www.OSTI.gov.

Cover Photos by Dennis Schroeder: (clockwise, left to right) NREL 51934, NREL 45897, NREL 42160, NREL 45891, NREL 48097, NREL 46526.

NREL prints on paper that contains recycled content. 


\section{Acknowledgments}

The authors thank Daniella Rough, Cristobal Munguia Chipana, and Rosendo Yone Ramirez Taza at Peru's Ministry of Energy and Mines for their valuable support and guidance in performing this study as well as the staff at Electro Oriente and GenRent International for providing all the necessary data and information about the Iquitos, Peru, power system. Thank you to Alex Aznar and Michael Craig at the National Renewable Energy Laboratory for their invaluable comments during the review process. Many thanks also to Gina Cady, our U.S. State Department and U.S. Agency for International Development contact within the Peru Mission. 


\section{Nomenclature or List of Acronyms}

DHI

DNI

ELOR

MINEM

NSRDB

PV

SEIN

TMY

USAID diffuse horizontal irradiance

direct normal irradiance

Electro Oriente

Ministerio de Energía y Minas (Peru)

National Solar Radiation Database

photovoltaic

El Sistema Eléctrico Interconectado Nacional (SEIN)

typical meteorological year

U.S. Agency for International Development 


\section{Executive Summary}

The National Renewable Energy Laboratory performed an evaluation of the technical and economic feasibility of incorporating solar photovoltaic (PV) resources into the Iquitos, Peru, power system at the request of Peru's Ministerio de Energía y Minas and funded within the joint U.S. State Department and U.S. Agency for International Development Leadership Compact program. The Iquitos power system is electrically islanded due to its remote location; heavy fuel oil is used to generate electricity in the system, leading to high electricity generation costs from high fuel prices. Solar PV has the potential to provide locally derived energy to ensure a reliable, affordable, and equitable power grid for the Iquitos region. The main findings from this report are:

- The solar resource in Iquitos, Peru, is suitable for solar development. Even though the solar resource in Iquitos is lower than other regions in Peru, the solar resource is still of relatively high quality to support solar development.

- The average expected capacity factor of a PV panel, using actual weather data from the last 20 years in Iquitos, is approximately $16 \%$. There is low seasonal variability in solar generation, which results in a similar generation profile throughout the year.

- As with all other power systems, there is no technical limit to the amount of solar PV that the Iquitos power system can integrate. Instead, the limit to solar PV deployment is economic in nature, based on how much cost a power system is willing to incur for a desired level of deployment.

- The amount of heavy fuel oil generation offset by a solar system depends on the size of the system installed and the instantaneous system-wide solar PV penetration that the Iquitos system operator might allow - this limit was not defined in this study, but it was introduced at a variety of levels to understand how this limit would impact PV deployment and curtailment.

- The analysis found that up to $15 \mathrm{MW}$ of solar PV generation capacity can be integrated into the Iquitos power system without experiencing significant curtailment when a relatively conservative maximum instantaneous system-wide solar PV penetration limit of $30 \%$ is implemented.

- Estimating the overall economic impacts of an installed PV system is a complex exercise - this analysis focused on calculating the costs savings associated with reduced heavy fuel oil use from the installation of a 10-MW PV system. A 10-MW PV system generating $19.3 \mathrm{GWh}$ per year (equivalent to $5.85 \%$ of the annual electricity demand) would reduce annual fuel-related generation costs by $\$ 2.1$ million.

- The instantaneous PV penetration limit has a large impact on when battery resources are needed to reduce annual curtailment to acceptable levels. For instance, in a system with a $30 \%$ instantaneous PV penetration limit, batteries are not needed until $20 \mathrm{MW}$ of PV are installed. In a system with a $70 \%$ instantaneous PV penetration limit, however, batteries are not needed until PV deployment reaches $40 \mathrm{MW}$.

- The amount of storage capacity needed to reduce solar PV curtailment to set levels increases with solar PV capacity installed, lower curtailment targets, and as the 
instantaneous penetration limit decreases. The cost of installing storage in the Iquitos system needs to be balanced with the savings achieved by reducing solar PV curtailment as well as the various other value streams that storage might provide. 


\section{Table of Contents}

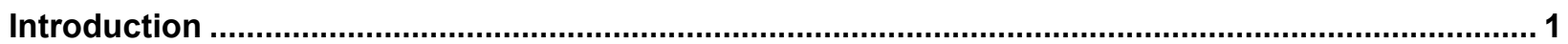

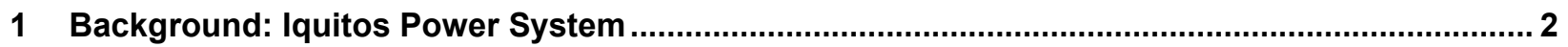

2 Solar Resource and Photovoltaic Performance Analysis for Iquitos .......................................... 6

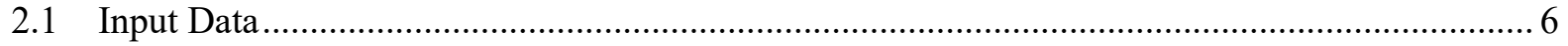

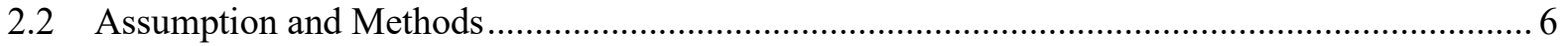

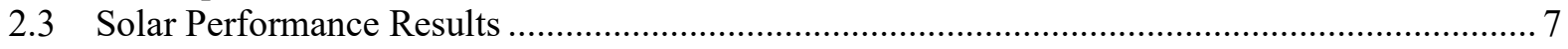

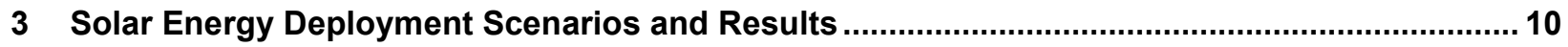

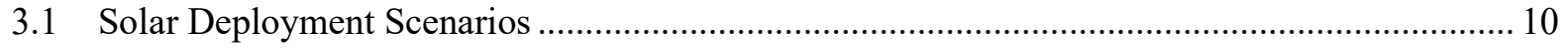

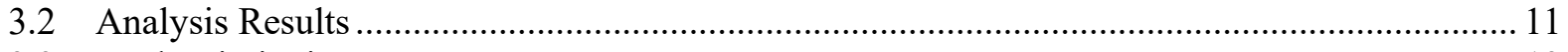

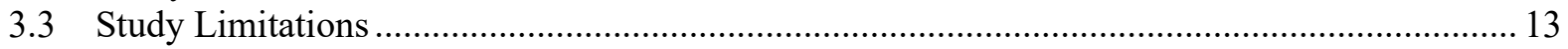

4 Impact of Energy Storage on Solar Photovoltaic Curtailment................................................. 15

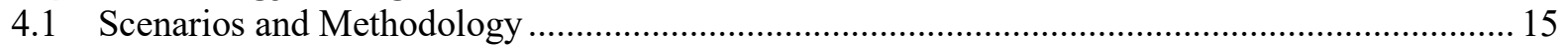

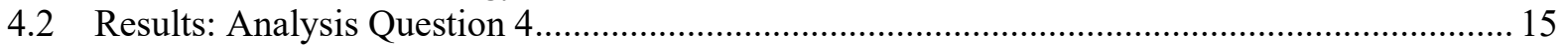

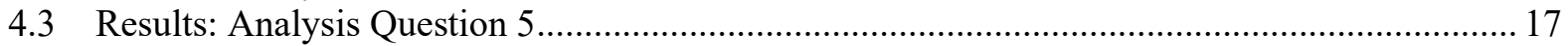

5 Technical Considerations and Dynamic Simulation Studies..................................................... 19

5.1 Technical Considerations: PV Integration ...................................................................... 19

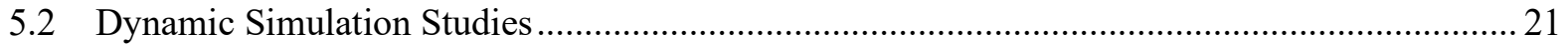

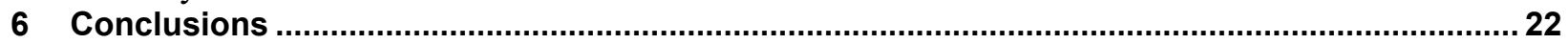

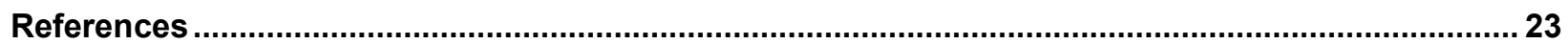

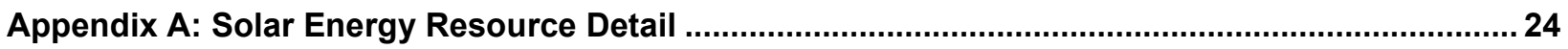

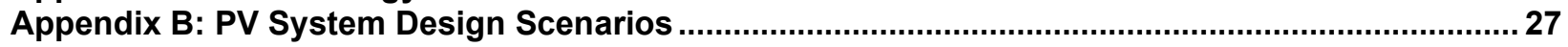

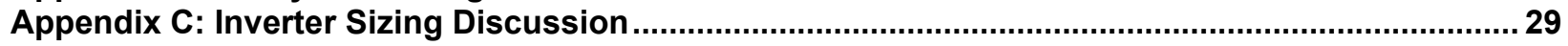




\section{List of Figures}

Figure 1. Annual electricity consumption in Iquitos power system (ELOR 2019) .................................. 3

Figure 2. Electricity demand: weekday (illustrative) ........................................................................... 4

Figure 3. Electricity demand: weekend day (illustrative) .................................................................... 4

Figure 4. Hourly electricity demand in Iquitos power system: annual profile (2016) (Note: X-axis

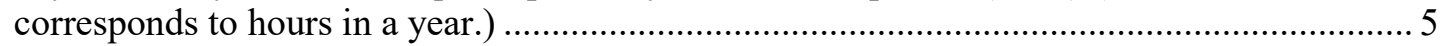

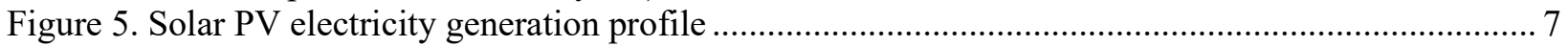

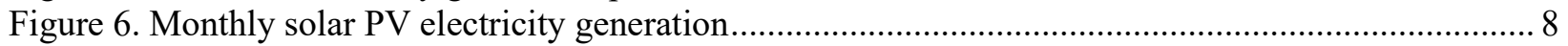

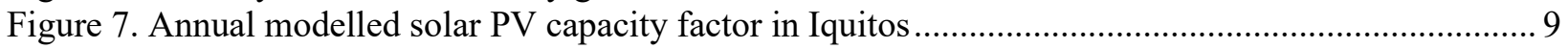

Figure 8. Annual solar energy penetration .................................................................................. 11

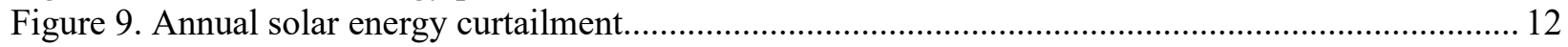

Figure 10. Annual curtailment (\%) for each sizing and battery scenario under 30\% (top), 50\% (middle), and $70 \%$ (bottom) instantaneous penetration limits ........................................................... 17

Figure A-1.Surface air temperature: typical meteorological year........................................................... 24

Figure A-2. Direct normal irradiance: typical meteorological year...................................................... 24

Figure A-3. Diffuse horizontal irradiance: typical meteorological year ............................................. 25

Figure A-4. Direct normal irradiance: daily profile for every month in a typical meteorological year...... 25

Figure A-5. Diffuse horizontal irradiance: daily profile for every month in a typical meteorological year26

Figure A-6. DC/AC ratio impact on average daily solar PV electricity generation profile 30

\section{List of Tables}

Table A-1. DC/AC Ratio Impact on Net Capacity Factor (Fixed Open-Rack System) 


\section{Introduction}

The Iquitos power system in Peru is electrically islanded from Peru's national grid because of its remote location in the Amazon rainforest. The electrical consumption of the Iquitos power system is relatively low compared to the overall demand of Peru's Sistema Eléctrico Interconectado Nacional (SEIN). At present, all electricity consumed within Iquitos is generated locally using internal combustion engines that burn heavy fuel oil, which is transported by ships along the Amazon River. The cost to transport this fuel—on top of the high cost of the fuel itself - leads to high electricity generation costs in Iquitos. In addition, burning heavy fuel oil to generate electricity causes negative environmental impacts, such as poor local air quality. The high cost of electricity generation is directly subsidized by Peru's government and a reduction in electricity generation costs will decrease the amount of subsidies paid to keep retail electricity tariffs affordable in the region.

Given recent global reductions in solar photovoltaic (PV) system costs and the local solar technical potential in the Iquitos region, Peru's Ministerio de Energía y Minas (MINEM) has expressed interest in understanding the potential impacts of integrating solar energy into the Iquitos power system. In particular, MINEM was interested in understanding (1) the technical considerations of integrating different levels of solar PV generation, (2) the associated impacts on power system variable generation costs and overall power system reliability of PV deployment, and (3) the potential value of battery energy storage systems to reduce PV curtailment in the event that PV systems are introduced into the Iquitos power system.

The main purpose of this report is to answer the following analysis questions related to solar PV deployment in Iquitos:

- Analysis Question 1-What are the key characteristics of the solar resource in Iquitos and how does this resource impact PV performance?

- Analysis Question 2-How much solar PV generation can the Iquitos power system reasonably integrate on an annual basis without experiencing excessive solar PV curtailment, given a range of instantaneous solar PV penetration limits?

- Analysis Question 3-What are the variable generation cost savings from displacing heavy fuel oil generation with solar PV generation?

- Analysis Question 4-How do energy storage resources impact the amount of PV curtailment and for each modelled scenario?

- Analysis Question 5: What is the amount of energy storage needed to reduce curtailment to targeted levels?

The analysis presented in this technical report was performed by the U.S. National Renewable Energy Laboratory (NREL) for MINEM as a first step in answering these questions. This report also details the need for a variety of additional analytical exercises which can further elucidate the potential impacts of solar PV generation on the reliability of the Iquitos power system. 


\section{Background: Iquitos Power System}

The Iquitos power system operates islanded from other power systems and serves a maximum electricity demand of close to $60 \mathrm{MW}$. Electricity is generated by burning fossil fuels, primarily heavy fuel oil, and limited amounts of diesel for starting up certain generating units. Electro Oriente (ELOR) is the electricity utility of Iquitos, operating the distribution network and delivering electricity to its connected customers. Historically, ELOR generated all the electricity in Iquitos with generators located in the middle of the city of Iquitos. Today, the generation of electricity is the responsibility of GenRent, a generation company whose power plants are located approximately $15 \mathrm{~km}$ north of Iquitos and connected via a single $60-\mathrm{kV}$ transmission line. Currently, ELOR generates electricity only during outages.

The majority of ELOR's generators are less flexible and more expensive to operate due to their age and lower thermal efficiencies. The three newest Wartsila generators operated by ELOR, however, installed in 2014, have thermal efficiencies comparable to the seven MAN generators, installed between 2017 and 2018, that are operated by GenRent. The Wartsila generators have an installed capacity of about 7.5 MW each, whereas the MAN generators have an installed capacity of approximately $11.5 \mathrm{MW}$ each, totaling a system generation capacity of approximately 103 MW.

The Iquitos power system requires approximately 300,000 MWh of generation annually. The cost of generating electricity in Iquitos remains one of the highest in Peru because of the high cost of heavy fuel oil. Previous power sector planning exercises examined the prospective development of a transmission line $(\sim 600 \mathrm{~km})$ through the Amazon rainforest, connecting Iquitos to the main SEIN power system to provide reliable and lower cost electricity; however, the high capital cost ( $\$ 500$ million) and environmental concerns of developing this transmission line have limited the feasibility of this option (División de Supervisión de Electricidad 2018). Thus, local solutions are likely required to ensure a reliable, affordable, and equitable power grid for the Iquitos region.

Importantly, the Iquitos power system has experienced a large increase in electricity consumption during the past decade. Figure 1 shows that annual electricity consumption in Iquitos has increased by more than $50 \%$ during the past nine years. Electricity is primarily consumed by the residential and commercial sectors because there is relatively little industrial activity in the region; most of the increase in electricity consumption is driven by an increase in deployment of air conditioning units in residential and commercial buildings. This trend is expected to continue in the future; the rate of this growth, however, is uncertain and currently forecasted by ELOR to be lower (ELOR 2019). This increase in electricity demand results in increased generation and overall fuel costs, which are passed on to ratepayers and might cause an increase in electricity generation subsidies. 


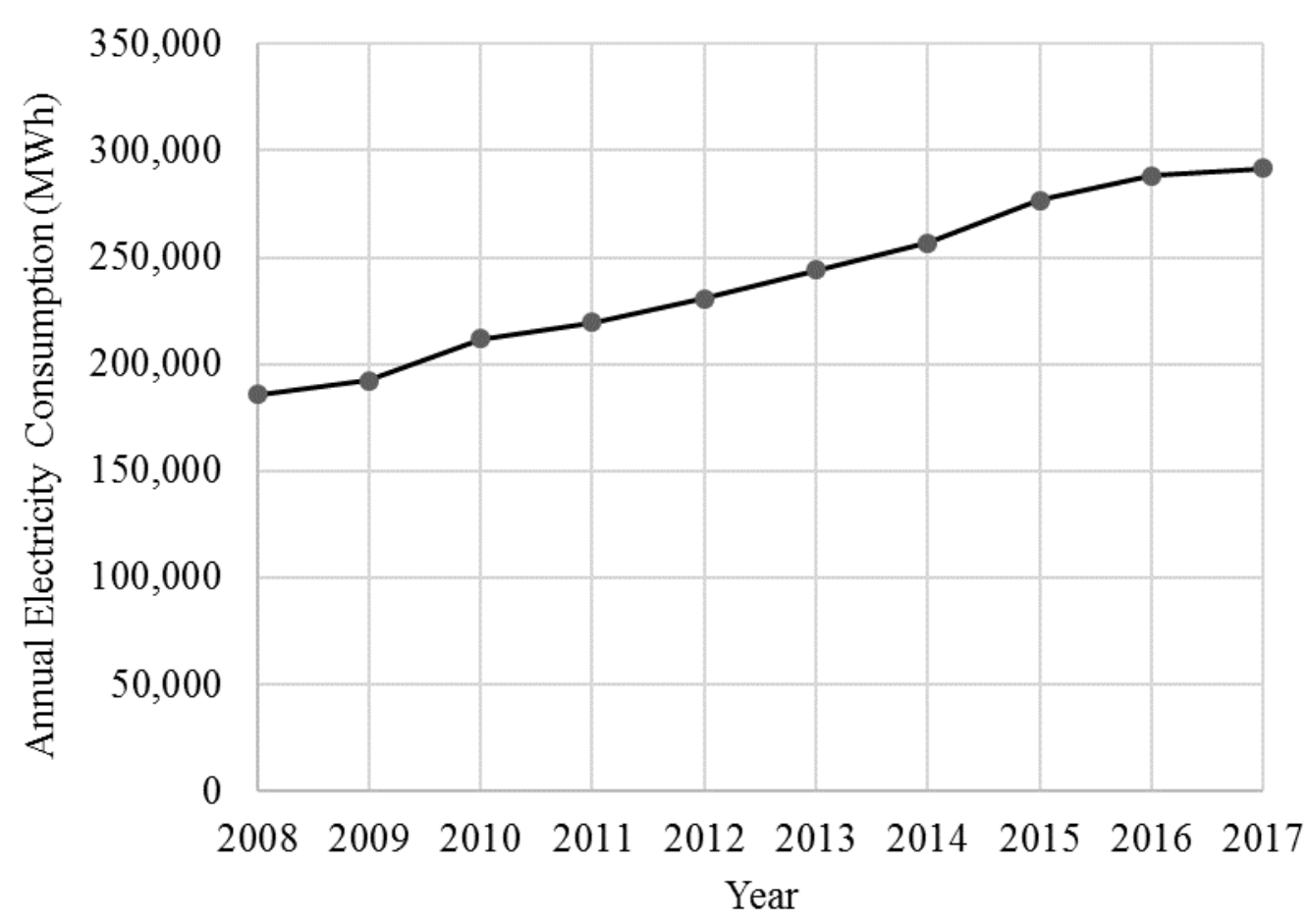

Figure 1. Annual electricity consumption in Iquitos power system (ELOR 2019)

Solar PV has been identified as a prospective mechanism to reduce average electricity generation costs in Iquitos moving forward. In principle, this would be possible if the annual variable cost savings associated with solar PV generation are less than contracted cost of solar PV electricity generation $^{1}$, plus the annuitized cost of any capital expenditures to support grid improvements required to support solar PV integration. The ability of the Iquitos power system to integrate solar energy depends, among other variables, on the daily and seasonal correlation between solar PV electricity generation and electricity demand, as well as on the operational flexibility of the other electricity generators. In principle, the new MAN internal combustion engines (as well as the Wartsila power plants) can be operated relatively flexibly, within some specific limits, and can assist in the integration of inverter-based, variable solar PV generation.

Figure 2 and Figure 3 show an illustrative electricity demand profile for a weekday and a weekend day in Iquitos, respectively. The two profiles are quite distinct. As in most power systems, electricity demand is higher during a weekday than it is during a weekend day. Moreover, the weekday profile has two peaks: one in middle of the day and the other in the evening. The weekend day, instead, has a single peak in the evening. The integration of solar PV generation would thus have relatively distinct impacts on the operation of the power system between these two segments of the week because of the different correlations between expected solar PV generation and electricity demand. Put differently, the daily profile of instantaneous solar energy penetration relative to the daily profile of electricity demand is different for both types of days.

\footnotetext{
${ }^{1}$ This assumes a power purchase agreement model where ELOR would purchase generation from a developer.
} 


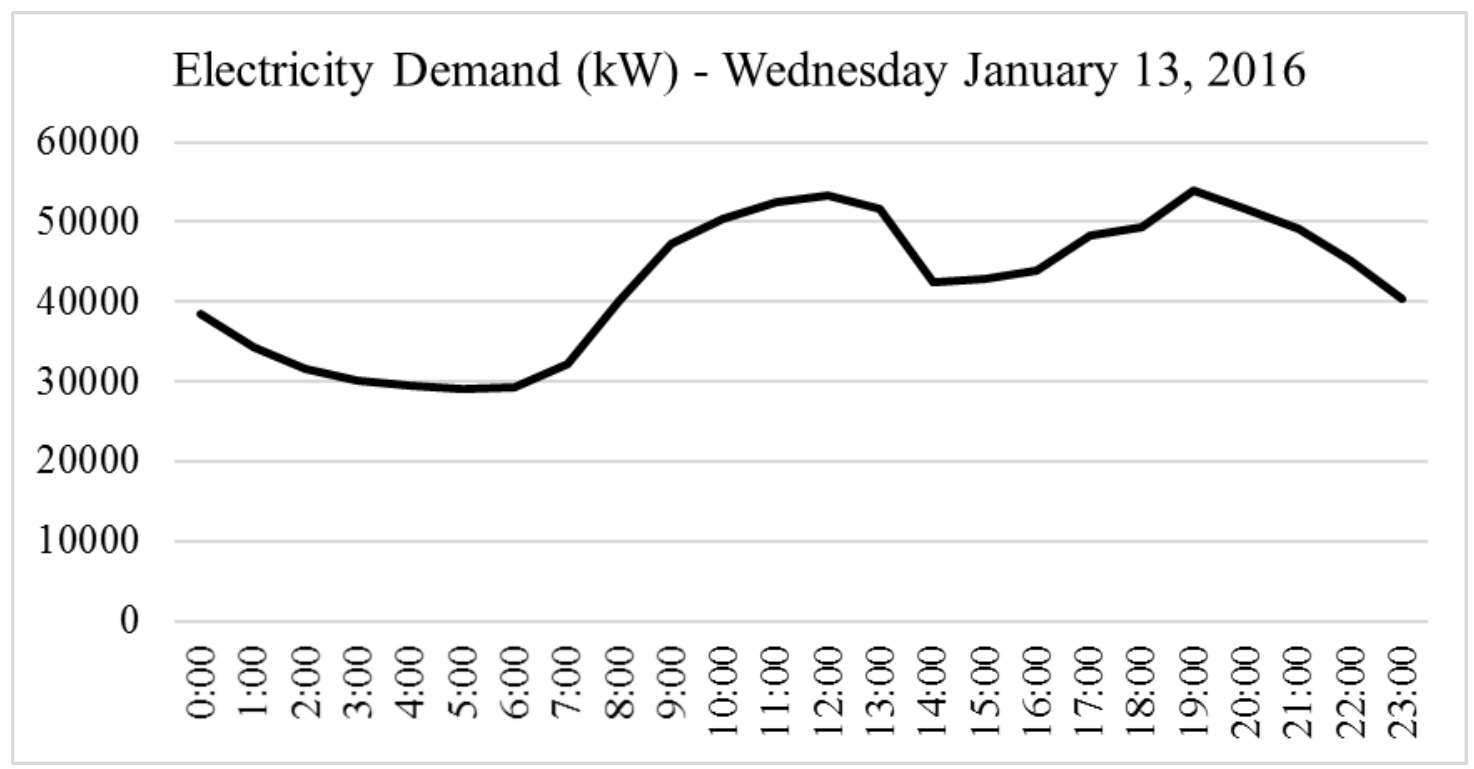

Figure 2. Electricity demand: weekday (illustrative)

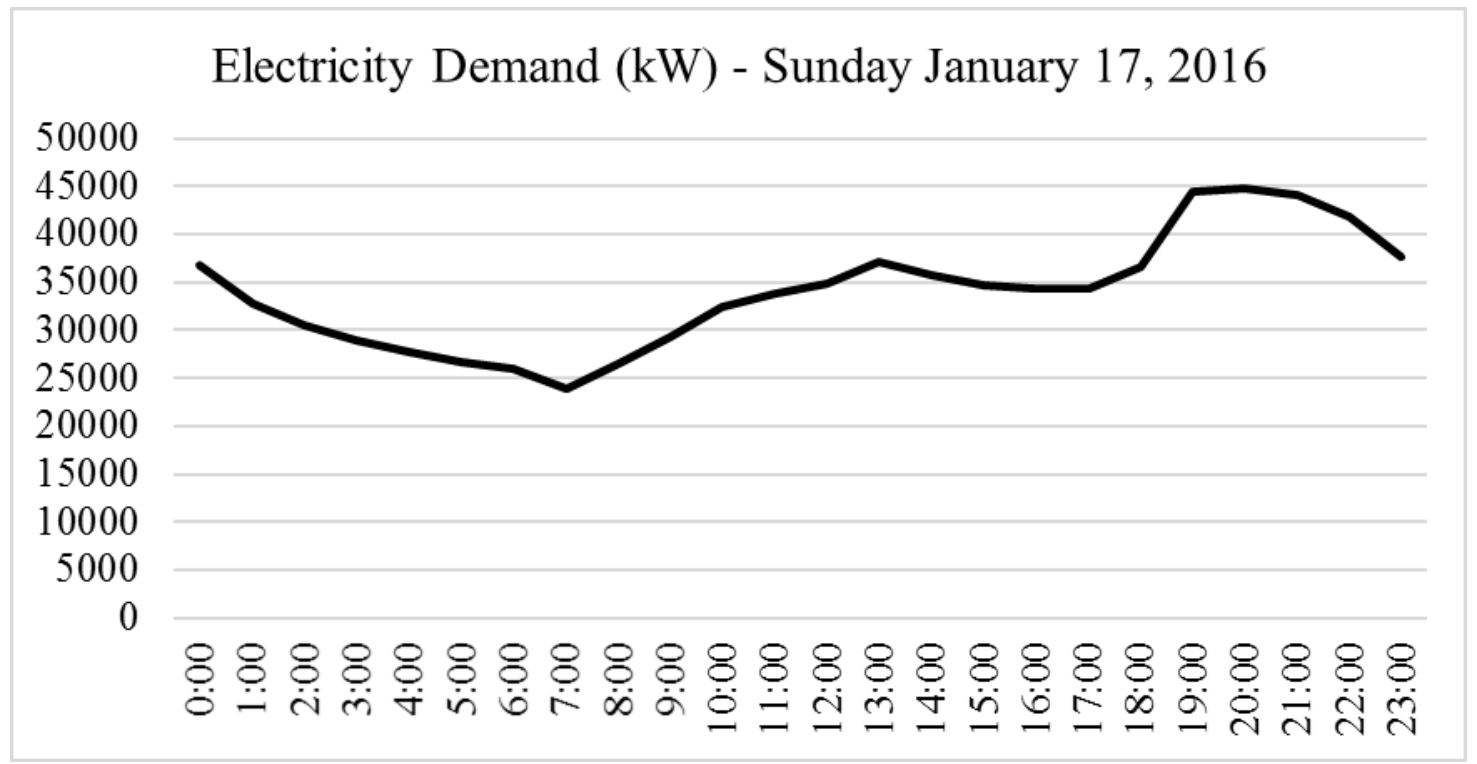

Figure 3. Electricity demand: weekend day (illustrative)

In general, when examining the impact of variable renewable energy resources on power systems, it is important to simulate the hourly (and even sub-hourly) operation of power systems for a full calendar year to capture trends and correlations in the seasonality of both electricity demand and renewable resources. While the Iquitos region does not have a visibly obvious seasonal pattern in demand (see Figure 4) or solar resource (see Figure 6)-likely due to its relatively constant temperatures and close proximity to the equator - it is nevertheless important to utilize detailed operational models to provide relevant analysis insights on the costs, benefits, and impacts of solar PV deployment. The hourly demand profile for the Iquitos power system in 2016 is displayed in Figure 4-this demand profile is utilized in the power system operational analysis described in Sections 3 and 4 of this report. 


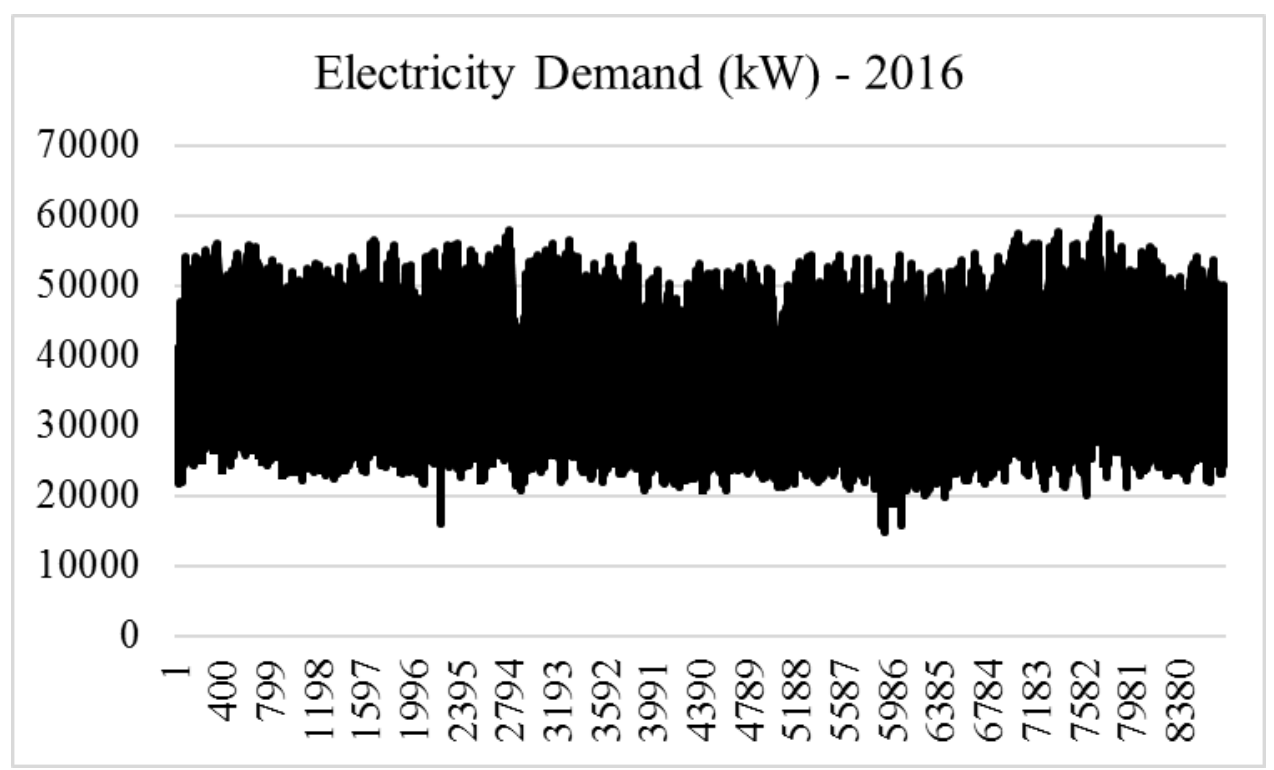

Figure 4. Hourly electricity demand in Iquitos power system: annual profile (2016) (Note: X-axis corresponds to hours in a year.)

The subsequent section describes the solar energy resource in Iquitos and the potential for solar PV generation. 


\title{
2 Solar Resource and Photovoltaic Performance Analysis for Iquitos
}

\author{
Analysis Question 1: What are the key characteristics of the solar resource in \\ Iquitos and how does this resource impact PV performance?
}

As a first step of the broader analysis, we characterize the expected operational performance of solar PV systems in Iquitos and create expected hourly solar generation profiles. We use solar resource data as an input (Section 2.1), and then employed the NREL System Advisor Model (SAM) to translate those data along with a variety of technical assumptions (Section 2.2) into hourly solar PV generation profiles (presented in Section 2.3). While there are other renewable resources available (e.g., wind, biomass) this report only examines solar energy potential in Iquitos. Wind resource in Iquitos is not available at any significant scale, and there are concerns about deforestation (a focus area for the regional government) associated with biomass.

\subsection{Input Data}

To analyze the solar energy resource in Iquitos, we use the National Solar Radiation Database (NSRDB) (Sengupta et al. 2018), a serially complete collection of meteorological and solar irradiance data sets for the United States and a growing list of international locations, which currently includes Iquitos, Peru. The database includes all the meteorological variables that affect solar PV electricity generation, mainly direct normal irradiance (DNI), diffuse horizontal irradiance (DHI), surface air temperature, and surface wind speed. These variables are the output of a physical model informed by satellite images and are available at a 30-minute temporal resolution and a 4-km by 4-km spatial resolution for the past 20 years (1998-2017). Further details of the solar energy resource are located within Appendix A

\subsection{Assumption and Methods}

To calculate the potential solar PV electricity generation in Iquitos for different solar PV system designs, we use the National Renewable Energy Laboratory's System Advisor Model (SAM). ${ }^{2}$

To analyze the daily and seasonal patterns of solar PV electricity generation in Iquitos, we run a SAM PVWatts model using a typical meteorological year (TMY) weather profile with a standard solar PV system design. This standard PV system design is used for the analyses performed in Sections 3 and 4 . For the purposes of this paper, a standard solar system design is:

- Thin-film PV modules

- Fixed open-rack array horizontal to the ground (0-degree tilt) ${ }^{3}$

- $\quad$ 1.4 DC/AC ratio (i.e., 1-MW inverter and 1.4-MW solar panels)

\footnotetext{
${ }^{2}$ System Advisor Model Version 2018.11.11 (SAM 2018.11.11), https://sam.nrel.gov/download.html.

${ }^{3}$ Note: An installed PV system would likely not be flat on the ground due to soiling and shading concerns, but this is provided to illustrate the solar resource potential in Iquitos.
} 
- $96 \%$ inverter efficiency

- $14.08 \%$ system losses (default in SAM, based on observed losses).

See Appendix B for different system design scenarios and sensitivities.

\subsection{Solar Performance Results}

Even though the solar resource in Iquitos is lower than other regions in Peru, there is still ample solar resource to support solar development. Figure 5 shows the average daily profile of electricity generation for each month during an average 24-hour period. Figure 6 shows the total monthly electricity generation for a typical meteorological year for the system design in section 2.2. Both figures highlight the lack of meaningful seasonal differences in terms of solar PV electricity generation.
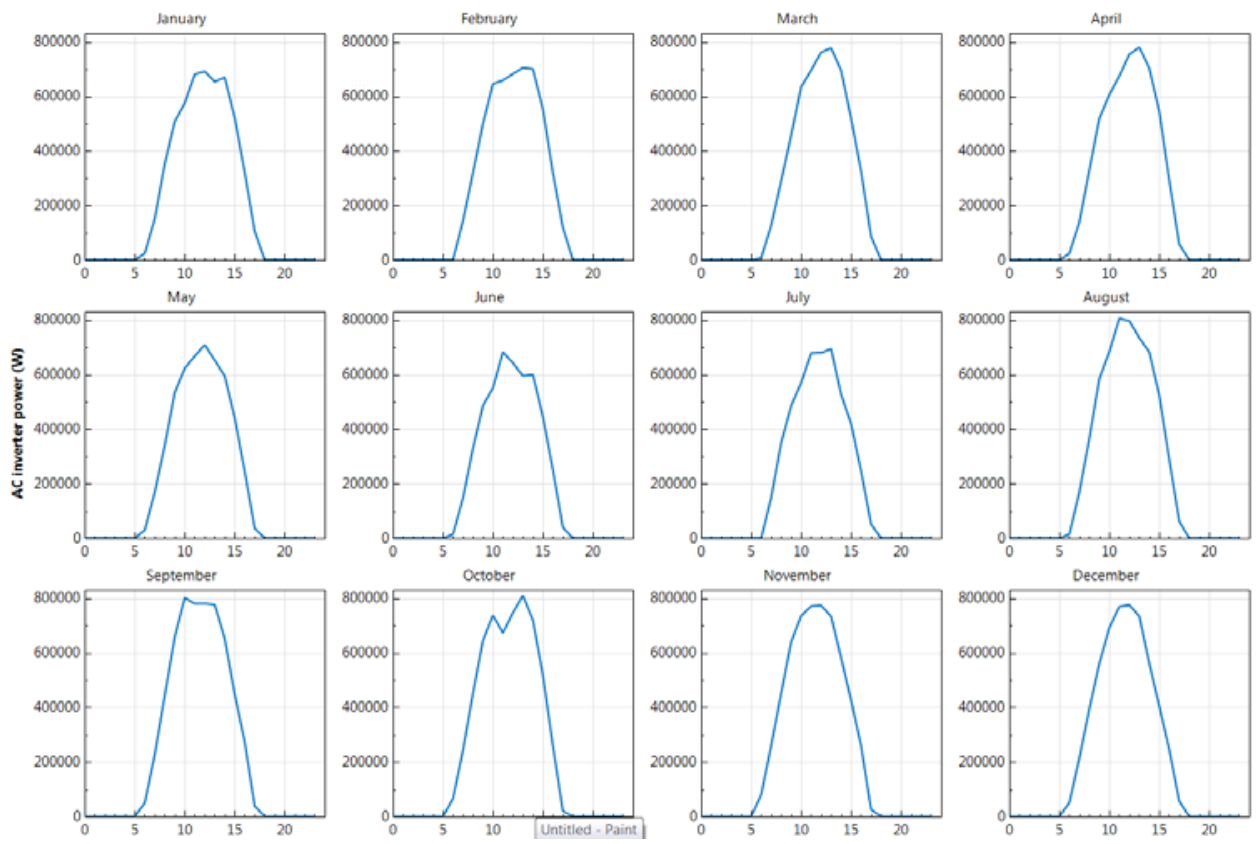

Figure 5. Solar PV electricity generation profile 


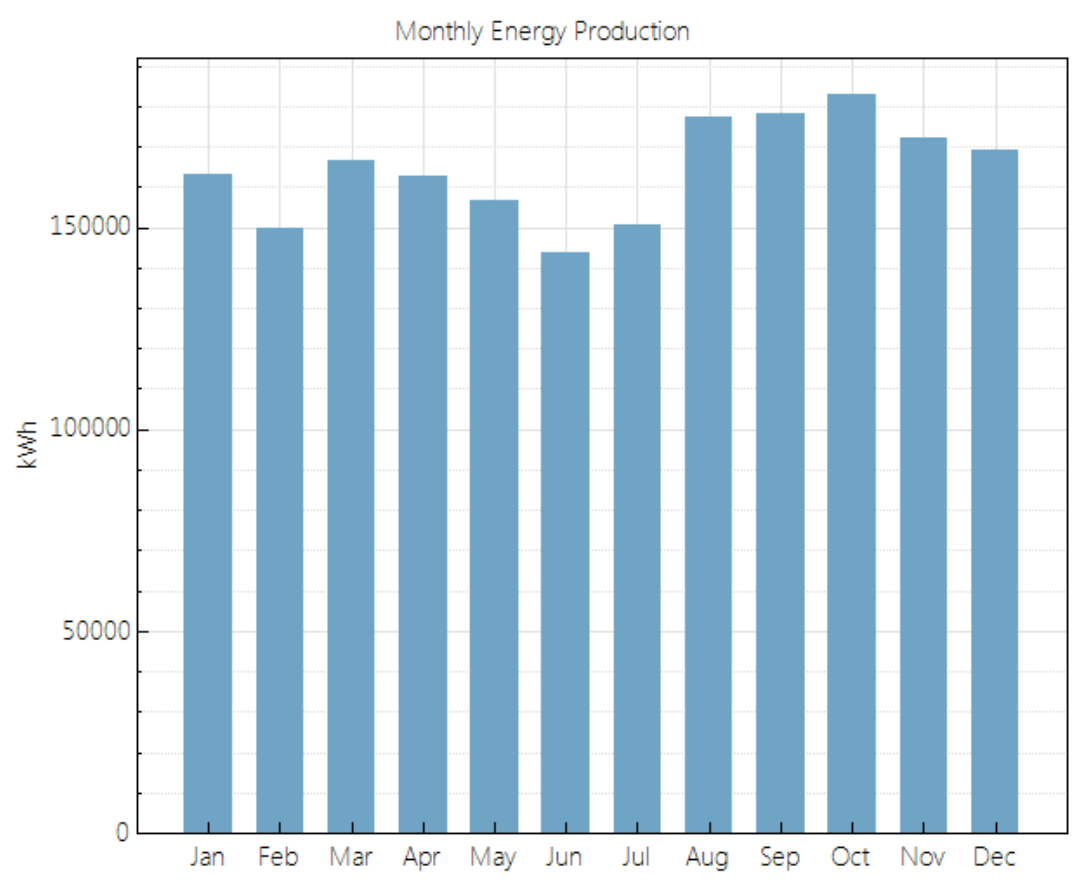

Figure 6. Monthly solar PV electricity generation

We also simulate solar PV electricity generation for all 20 years of actual meteorological data located in the NSRDB. Figure 7 shows the average annual capacity factor between 1998 and 2017. For the system design in section 2.2 , the average annual capacity factor is $16.1 \%$, which corresponds with the capacity factor calculated using TMY data (see Appendix B). Annual generation for this system is $1,973 \mathrm{MWh} / \mathrm{yr}$.

Notably, the interannual variability of solar PV electricity generation in Iquitos is not very large. The difference between the year with the highest capacity factor (1998) and the year with the lowest capacity factor (2010) is approximately $7 \%$. In other words, during this 20 -year period, no annual solar PV net capacity factor deviates more than approximately $3.5 \%$ from the 20 -year average. 


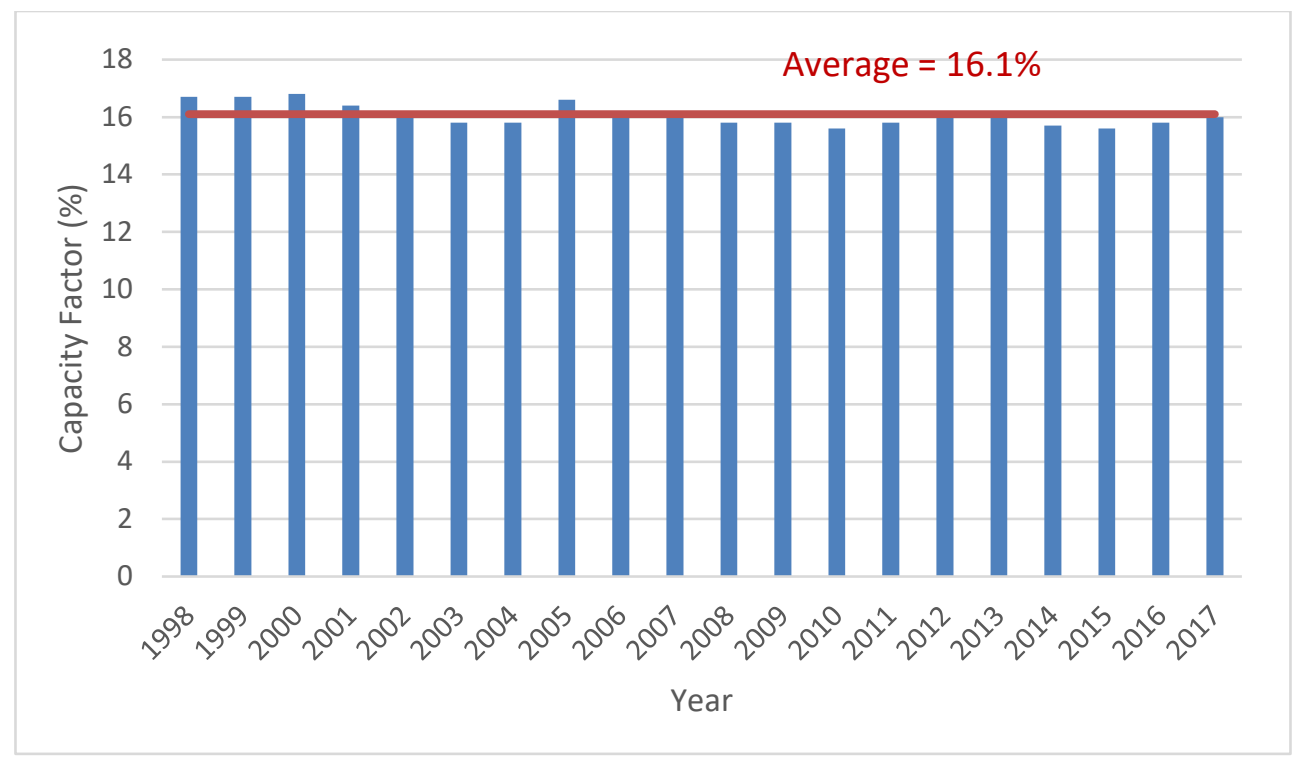

Figure 7. Annual modelled solar PV capacity factor in Iquitos 


\title{
3 Solar Energy Deployment Scenarios and Results
}

\author{
Analysis Question 2: How much solar PV generation can the lquitos power system \\ reasonably integrate on an annual basis without experiencing excessive solar PV \\ curtailment, given a range of instantaneous solar PV penetration limits? \\ Analysis Question 3: What are the variable generation cost savings from displacing \\ heavy fuel oil generation with solar PV generation?
}

In this section, we perform a time-series analysis using calculated solar PV generation profiles (see Section 2) and a historical electricity demand profile (see Section 1) to calculate an hourly solar PV penetration level as a percentage of electricity demand (which we refer to as instantaneous penetration of PV generation). Based on different assumed instantaneous penetration limits for nonsynchronous generation, the analysis determines both the potential for fossil fuel generation displacement, as well as the extent of solar PV curtailment that result from a range of solar PV deployment levels.

The system instantaneous PV penetration limit is dependent on operational characteristics of the power system and available generation. The limit is usually determined by the system operator after performing dynamic studies of the system to determine its stability after a disturbance for a series of scenarios and conditions. Section 5 provides a detailed discussion on the parameters that affect this limit, the details of the studies that must be done to evaluate the limit, and different ways to increase this limit for a system while maintaining the same reliability of the system. However, because this analysis does not include a dynamic study, instantaneous PV penetration limits are a variable that is tested, rather than a fixed quantity.

To study the full impact of integrating PV into the operation of the Iquitos power system, this analysis would need to run a production cost model (unit commitment and economic dispatch model) that would simulate generation commitment decisions as well as hourly (or sub-hourly) generation dispatch decision. Since the Iquitos power system is operated by running seven generating units that are the same (and they are currently only dispatched between $7 \mathrm{MW}$ and 10 MW, a range that results in only a few percentage points difference in thermal efficiencies,), there is no need to run a detailed optimization model to evaluate the impact of different penetration of solar PV power on the commitment and dispatch decisions for the seven synchronous machines. For an initial assessment of incorporating solar PV into the Iquitos power system, this study takes a simplified approach by performing a time-series analysis.

\subsection{Solar Deployment Scenarios}

The analysis explores 45 scenarios that vary in terms of the total system installed solar PV capacity and the system instantaneous nonsynchronous generation penetration limit. Fifteen different solar PV capacity scenarios (5 MW to $50 \mathrm{MW}$ in 5-MW increments, and $50 \mathrm{MW}$ to 100 MW in 10-MW increments) were each modelled for three different system instantaneous nonsynchronous generation penetration limit scenarios $(30 \%, 50 \%$, and $70 \%)$. 


\subsection{Analysis Results}

Figure 8 and Figure 9 show the annual solar energy penetration level that the modelled Iquitos power system reaches and the associated annual solar energy curtailment, respectively, as a function of installed solar PV capacity for different allowed maximum instantaneous solar PV penetration constraints $(30 \%, 50 \%$, and $70 \%)$.

We observe that up to $15 \mathrm{MW}$ of solar PV generation capacity can be integrated into the Iquitos power system without experiencing significant curtailment when a maximum instantaneous solar PV penetration of $30 \%$ is considered. The instantaneous solar penetration limit has a larger impact on curtailment as the PV system size increases. Increasing the solar penetration limit results in annual curtailment reduction as well. If the system can manage only a maximum instantaneous solar PV penetration of $30 \%$ and the system does not have any energy storage, an installed solar PV generation capacity of more than $15 \mathrm{MW}-20 \mathrm{MW}$ would lead to significant curtailment, which would reduce the economic viability of the solar PV power plants. If the maximum instantaneous solar PV penetration the system can manage is $50 \%$ or $70 \%$, the installed solar PV generation capacity beyond which the economic viability of the solar PV power plants would be reduced is approximately $25 \mathrm{MW}-30 \mathrm{MW}$ and $40 \mathrm{MW}$, respectively.

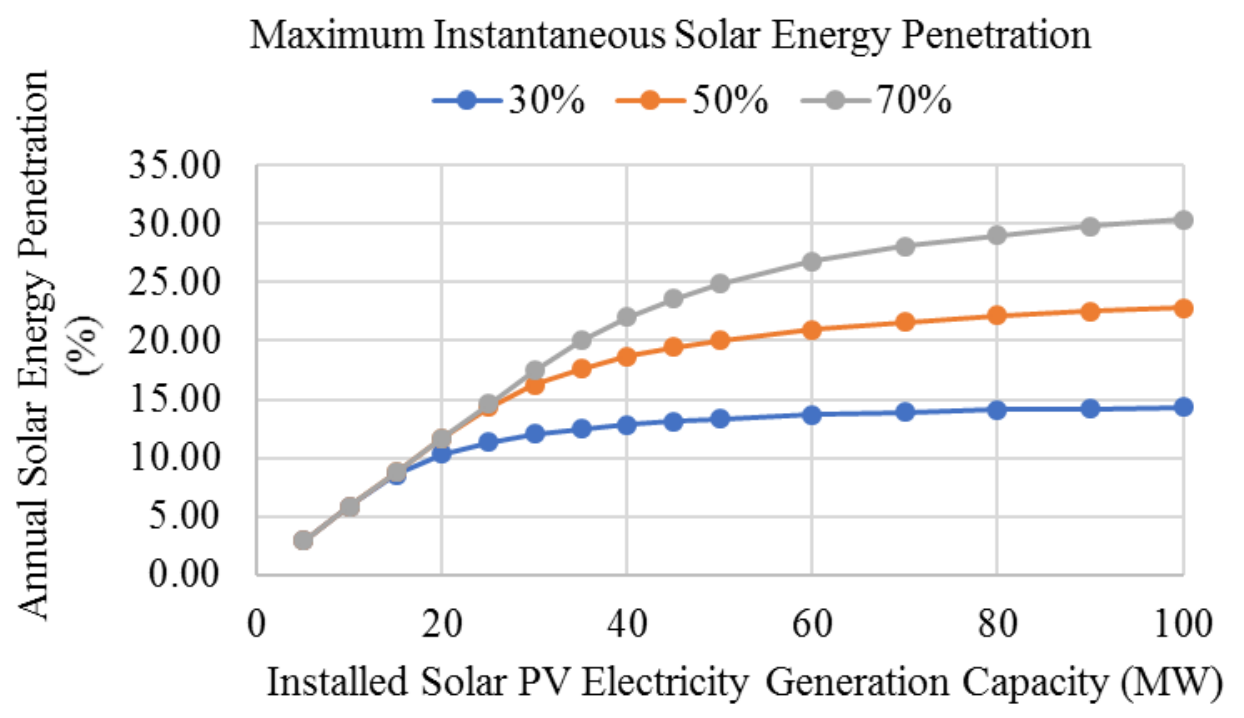

Figure 8. Annual solar energy penetration 


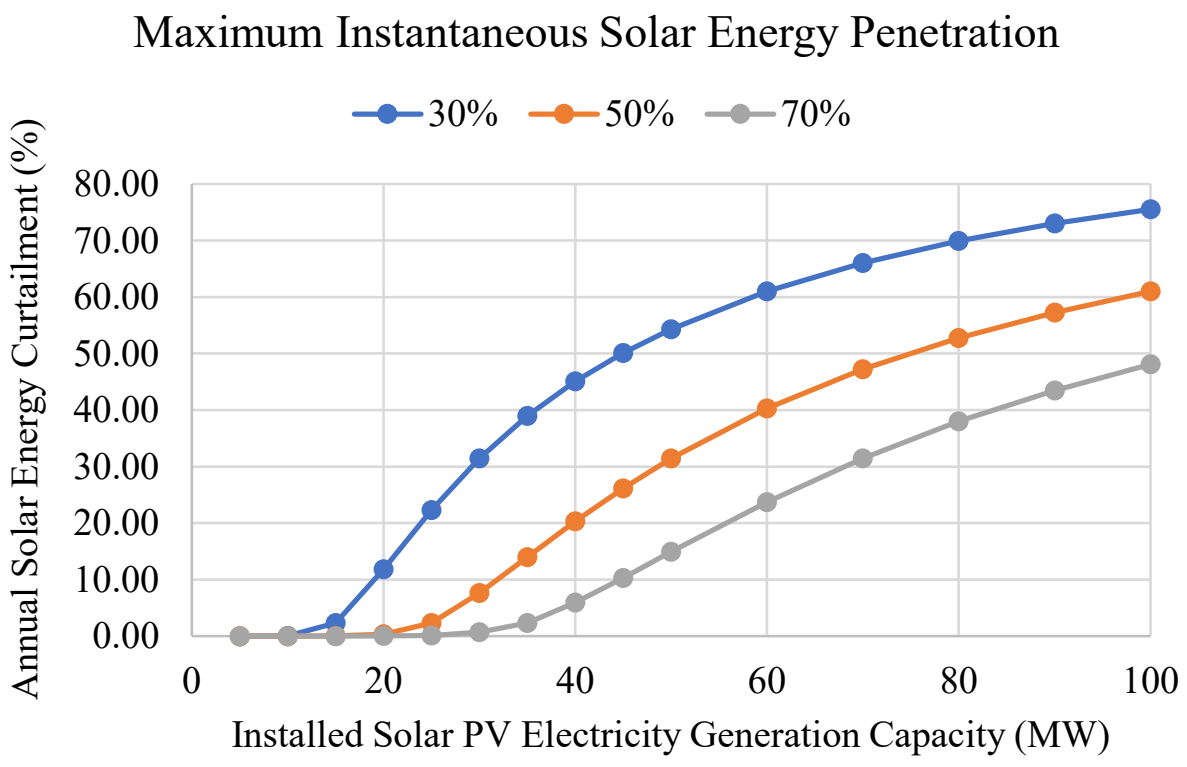

Figure 9. Annual solar energy curtailment

This analysis did not estimate the amount of heavy fuel oil reductions from different solar PV installation scenarios. To estimate this value, this analysis would need to estimate the average heat rate of generators. These numbers are confidential to the operators and are highly dependent on the actual operation of the plants. In summation, the percentage increase in annual solar energy penetration is directly equal to the percentage decrease in annual oil-based electricity generation. This percentage increase in solar energy generation is proportional but not directly equal to the percentage decrease of the annual fuel costs based on the lack of heat curve information for the generators. As well as not having information for the heat curves, fuel costs vary during the year and would have an impact on the change in variable fuel costs.

To calculate initial economic impacts of solar installation, this analysis examines a scenario of installing a 10-MW PV system and calculates the associated reduction in variable fuel costs that the deployment of this PV system results in. The major economic impact of increasing penetrations of solar PV is related to the reduction of heavy fuel oil burnt by the conventional generators. In today's Iquitos power system, the fuel $\operatorname{cost}^{4}$ for electricity generation is approximately $\$ 110 / \mathrm{MWh}$. To evaluate the economic viability of integrating a certain level of solar PV capacity, the generation or power purchase costs associated with the new solar PV system would need to be compared with reduction in annual fuel costs that PV generation results in. As an example, if the Iquitos power system deployed $10 \mathrm{MW}$ of solar PV, the PV system would generate $19.3 \mathrm{GWh}$ per year (based on TMY weather data), equivalent to $5.85 \%$ of the annual electricity demand $(330 \mathrm{GWh})$ and reduce variable fuel costs by $\$ 2.1$ million per year ${ }^{5}$. This implies that if the all-in cost of PV generation, including grid upgrade costs and increased

\footnotetext{
${ }^{4}$ Fuel cost in this case is the fuel component of the variable generation cost for running these generators. It does not include O\&M or other costs. The fuel cost might vary throughout the year depending on fuel commodity prices. ${ }^{5}$ In this scenario, with a $30 \%$ instantaneous PV penetration limit, there is no curtailment of solar generation-in other words, all PV generation directly offsets heavy fuel oil use.
} 
generator cycling costs, was less than $\sim \$ 109 / \mathrm{MWh}$, then PV deployment might make economic sense from a system perspective in Iquitos.

Importantly, the integration of solar PV power in the Iquitos power system would not reduce fixed electricity generation costs. A similar level of nonfuel operation-and-maintenance (O\&M) costs would be required to operate power plants reliably with integration of solar resources. A reduction of electricity generation from the conventional power plants would not impact the labor costs of operating the system, especially given the unavailability of solar power between sunset and sunrise as well as the increased system variability that would lead to an increase in the cycling of the conventional generators. In other words, the nonfuel O\&M costs per MWh of electricity generated by conventional generators would increase with the integration of solar power. To reduce solar curtailment thermal generators could be dispatched at very low generation levels $(30 \%-50 \%$ of rated capacity) reducing thermal efficiencies and leading to a higher average per MWh fuel cost for individual plants, though overall system operational costs would likely decrease.

The marginal annual fuel cost savings of increasing solar PV penetration in the Iquitos power system will decrease with increasing penetrations of solar PV because of the need for increased solar curtailment and the reduced efficiency of the thermal generators (i.e., higher cycling and dispatch at reduced thermal efficiency generation levels). At a certain level of solar PV penetration, the integration of energy storage will decrease PV curtailment and increase system fuel cost savings. The economic viability of integrating solar PV with or without energy storage depends on the cost of building solar PV power plants and energy storage devices in Iquitos. These depend on the capital costs of different solar PV and storage technologies as well as the cost and availability of land for the development of such projects.

\subsection{Study Limitations}

The major limitation of this portion of the analysis is the unknown maximum instantaneous solar PV penetration that the Iquitos power system can currently sustain while maintaining its reliability metrics. The study therefore provides a series of suggestions on how to evaluate the maximum instantaneous solar PV penetration (which will affect the ability of the system to integrate larger amounts of solar energy) as well as a series of potential methods to increase the ability of the system to enhance its ability to integrate higher instantaneous penetrations of nonsynchronous generation.

Other limitations of this study that could be explored in the future include the potential impact of solar PV electricity generation uncertainty and short-term variability (second to minutes) on the need to modify spinning reserve requirements, which could, in turn, increase the variable generation costs of synchronous generation because of the reduced thermal efficiency dispatch levels and increased maintenance requirements, even if the total system costs could still be reduced. A more detailed analysis of solar PV's impact on overall generation costs is needed to identify the tradeoffs for incorporating variable resources.

In addition to the ability of the system to integrate high instantaneous penetrations of inverterconnected generation, the Iquitos power system will be limited to how much solar energy it can integrate by the availability of suitable land for solar PV development. The availability of land for solar PV development will also impact the possibility to locate solar PV power plants in a 
distributed way to reduce the overall system variability and reduce the risks associated with the loss of a single power plant. In other words, the variability and the negative reliability impacts of a single 20-MW solar plant will always be greater than the impacts of four 5-MW solar plants. 


\title{
4 Impact of Energy Storage on Solar Photovoltaic Curtailment
}

\author{
Analysis Question 4: How do energy storage resources impact the amount of PV \\ curtailment and for each modelled scenario?
}

Analysis Question 5: What is the amount of energy storage needed to reduce curtailment to targeted levels?

The need to curtail solar PV generation increases with installed solar PV capacity and with lower maximum allowable instantaneous solar PV penetration limits (see Section 3). One way to decrease solar PV curtailment is to utilize energy storage for "temporal arbitrage"-or, in other words, using otherwise curtailed solar PV electricity generation to charge the storage device during low demand periods and discharge the battery when solar PV electricity generation is not available or is less than the maximum instantaneous penetration the system can sustain.

In this section, we present an analysis of the impact of storage deployment on annual solar curtailment in different scenarios. These scenarios include different installed capacities of 4-hour battery storage devices, different installed solar PV capacities, and different maximum instantaneous solar PV penetration limits. This section also details the amount of energy storage resources needed to reduce solar PV curtailment to targeted levels.

\subsection{Scenarios and Methodology}

The first battery analysis explores 45 scenarios that vary in terms of total solar PV capacity installed, the power rating of the 4-hour battery, and the system instantaneous PV penetration limit. We model five different solar PV deployment scenarios (10 MW, $20 \mathrm{MW}, 30 \mathrm{MW}, 40$ $\mathrm{MW}$, and $50 \mathrm{MW}$ ) with four different 4-hour battery storage capacities (No storage (0 MW), 1 $\mathrm{MW}$, and $2 \mathrm{MW}$ ) and three different system instantaneous nonsynchronous generation penetration limit scenarios $(30 \%, 50 \%$, and $70 \%)$. Note that generation from battery devices are accounted for as contributing to the solar PV penetration limit, as they also rely on inverters to inject energy into the power system.

A second battery analysis utilizes a simple optimization model to evaluate the capacity of a 4hour battery storage needed to reduce annual solar PV curtailment to three different target levels: $5 \%, 3 \%$, and $1 \%$ for eight different scenarios that vary in terms of system total solar PV capacity (20 MW, $30 \mathrm{MW}, 40 \mathrm{MW}$, and $50 \mathrm{MW}$ ) and in terms of the system instantaneous nonsynchronous generation penetration limits (30\% and 50\%). Each scenario assumes a 90\% round-trip efficiency for the battery systems.

\subsection{Results: Analysis Question 4}

For each of the scenarios detailed above, this analysis calculates the annual solar curtailment as a percentage of annual solar generation for various battery sizes. Except for scenarios that did not 
experience solar curtailment with no battery (mainly small PV system sizes with a 50\% and 70\% instantaneous penetration limit), installing a battery reduced the annual curtailment levels. A reduction in annual solar PV curtailment corresponds to a slightly lower reduction in electricity generation from the conventional generators, due to round-trip efficiency losses in the battery.

Figure 10 details the impact on annual solar curtailment from installing batteries in the Iquitos system under different instantaneous penetration limits.

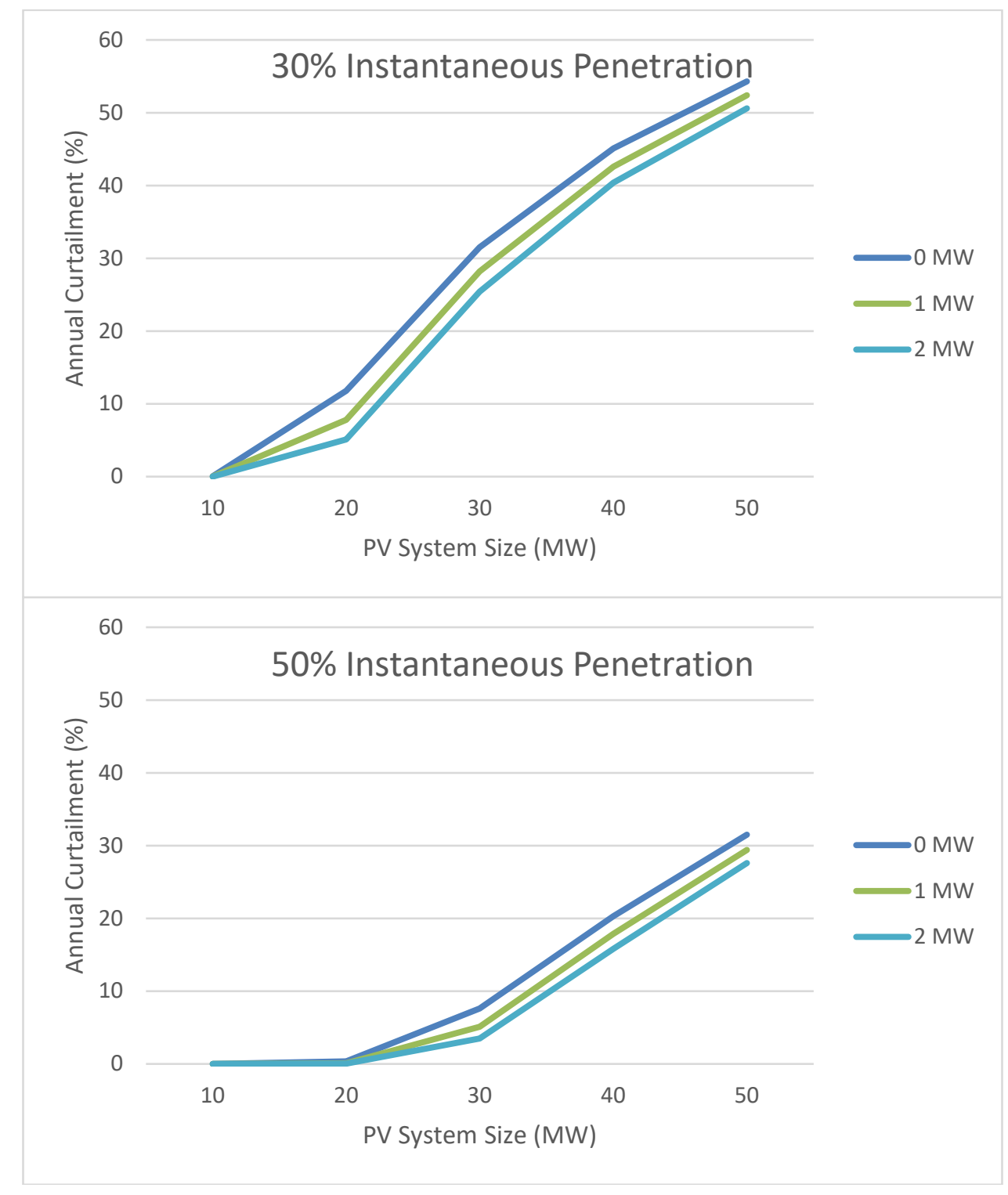




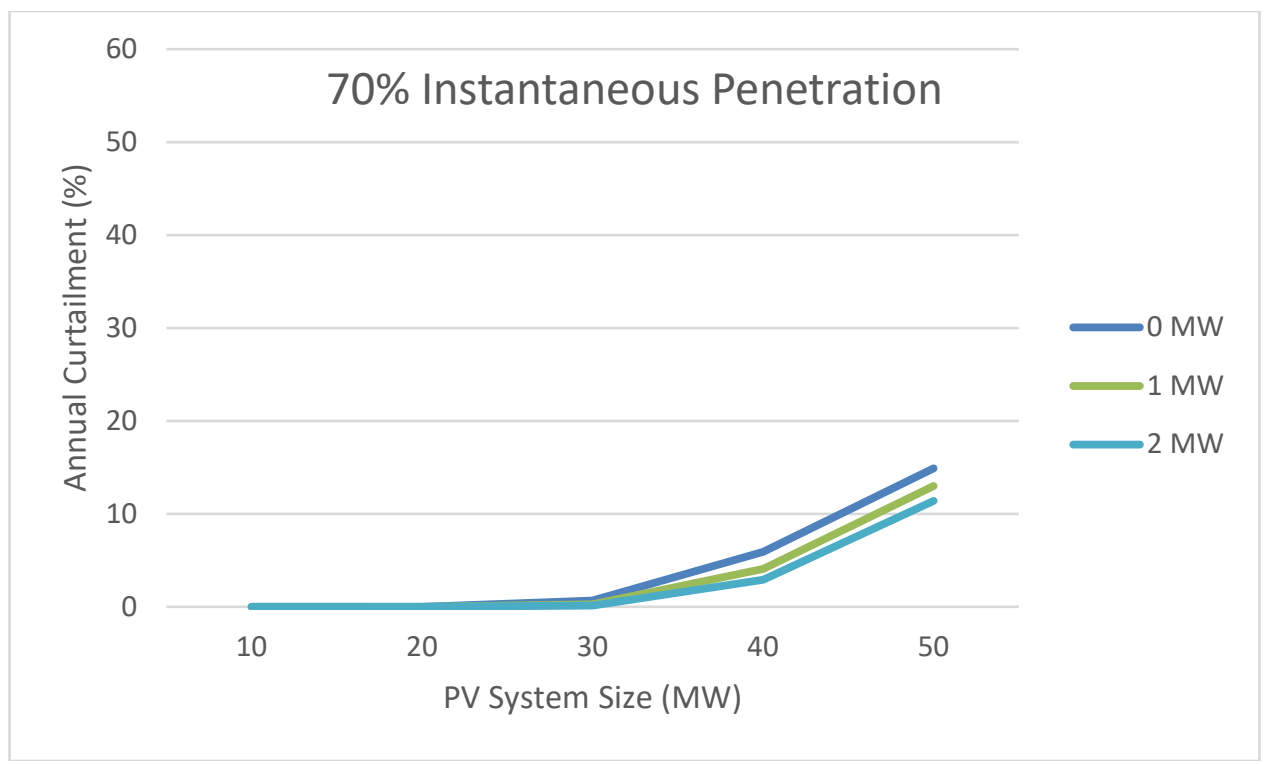

Figure 10. Annual curtailment (\%) for each sizing and battery scenario under $\mathbf{3 0 \%}$ (top), $\mathbf{5 0 \%}$ (middle), and $70 \%$ (bottom) instantaneous penetration limits

Overall, the instantaneous penetration limit has a significantly larger impact on solar PV curtailment than deploying a battery of any of the sizes modelled. However, batteries might still be a useful tool to reduce curtailment under higher solar PV penetrations. Thus, the Iquitos system operator will need to consider the costs (if any) associated with increasing instantaneous penetration limits and balance those against the capital costs of installing battery resources and the overall economic impact of reducing solar PV curtailment.

\subsection{Results: Analysis Question 5}

Figure 11 shows the capacity of a 4-hour battery storage needed to reach different solar PV curtailment targets $(5 \%, 3 \%$, and $1 \%)$ for 2 different maximum instantaneous solar PV penetration limits $(30 \%$ and $50 \%)$. 


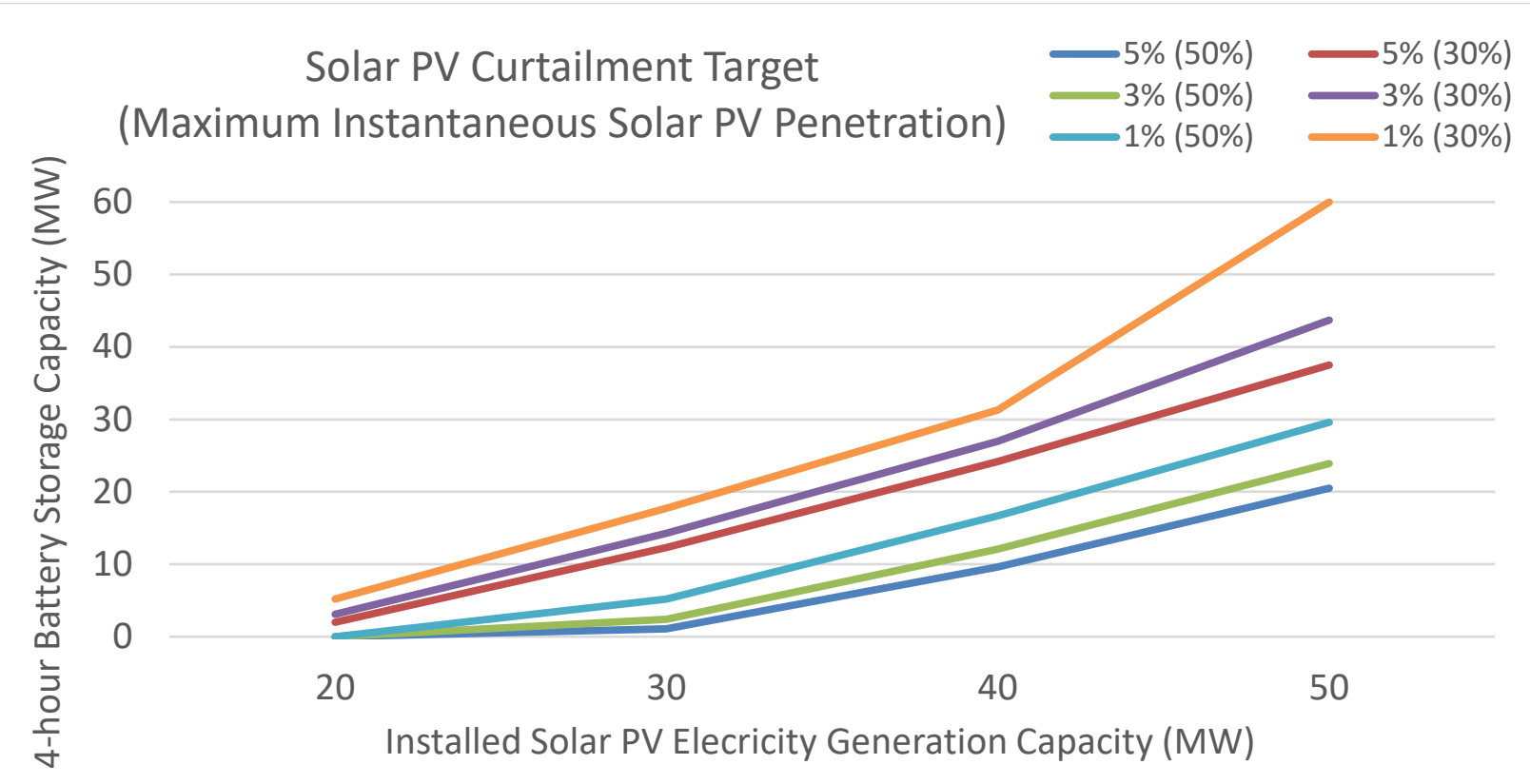

Figure 11. Capacity of a 4-hour battery storage (with a $90 \%$ round-trip efficiency) needed to reach three different solar PV curtailment targets for two different maximum instantaneous solar PV penetration limits

At a high level, the amount of storage capacity needed to reduce solar PV curtailment to set levels increases with solar PV capacity and with a lower curtailment target. For example, if the Iquitos power system has a total solar PV capacity of $30 \mathrm{MW}$, and it is limited a by a maximum instantaneous solar PV penetration of 50\%, a 4-hour battery with a capacity of $1.1 \mathrm{MW}$ would limit annual solar PV curtailment to 5\%. To further reduce annual solar PV curtailment to $3 \%$ or $1 \%$, the battery would need to have a capacity of $2.4 \mathrm{MW}$ or $5.2 \mathrm{MW}$ - this suggests that the marginal value of battery storage declines with increasing capacity. Overall, the optimal size of a 4-hour battery storage in the Iquitos will depend, among other parameters, on the total solar PV capacity deployed on the system, the cost of solar PV to the system (likely via a power purchase agreement with a private developer), the capital cost of battery storage, and the magnitude of fuel cost savings that would be further increased by the battery energy storage system through incremental reductions in solar PV curtailment). Put succinctly, the capital cost of installing a battery energy storage system in the Iquitos power system needs to be balanced with the potential savings achieved by reducing solar PV curtailment and further displacing heavy fuel oil use. 


\section{Technical Considerations and Dynamic Simulation Studies}

As discussed, in Section 3, the ability to incorporate variable, inverter-based generation is dependent on operational characteristics of the power system and generation available. The "optimal" build out generation resources is dependent on the ability to incorporate these resources, along with reliability, electrical stability, and cost concerns. This section will discuss technical considerations for setting the instantaneous limit for inverter-based (nonsynchronous) generation and will detail electrical studies needed to address the reliability and stability of the Iquitos electrical system.

\subsection{Technical Considerations: PV Integration}

The major variables that affect the ability of a power system to integrate different levels of instantaneous inverter-based, variable solar PV generation include:

- Primary and secondary frequency control capabilities of the online synchronous generators

- System inertia at different generation and load conditions (primarily determined by the number of synchronous generators online and the system loads)

- Dispatch level of the online synchronous generators, their ramping capabilities, and their minimum and maximum generation levels

- Power system reliability metrics the system must respect

- Possibility to shed and/or control electricity loads

- Availability of energy storage systems, including state of charge and ramping capabilities

- Number, capacity, and geographic distribution of solar PV power plants operating

- Capability of the solar PV power plant inverters to provide frequency control.

To determine an approximate method (without performing any dynamic simulation of the power system) of the maximum instantaneous penetration of solar PV electricity generation with which the current Iquitos power system could operate, without negatively affecting its current ability to meet load and operate within its reliability-driven operational limits, we assume that the system is able to sustain the loss of its largest contingency. In the present system, the largest contingency is one of the new MAN generation units, which has a nominal generation capacity of $11.6 \mathrm{MW}$. If we assume that these generators are never fully dispatched and that they always operate in droop mode below their maximum generation capacity to provide spinning reserves, dispatched at $10 \mathrm{MW}$, the system should be able to recover from the loss of one of these units, or from the loss of $10 \mathrm{MW}$ of generation. We therefore assume that the system can recover from the instantaneous loss of $10 \mathrm{MW}$ of solar PV electricity generation. In reality, when the power system is operating with $10 \mathrm{MW}$ of solar PV electricity generation, the inertia in the system and the available primary and secondary frequency responses might be less than without any solar power because there could be fewer synchronous generation units online. To account for this, the control systems of the online synchronous generators would need to be adjusted to ensure that the system can recover from the generation loss of $10 \mathrm{MW}$.

The maximum instantaneous solar energy penetration level that a power system can sustain while maintaining its reliability can be increased in several ways. The following nonexhaustive 
list includes some examples of how a system can further increase its capability to integrate higher instantaneous penetrations of solar PV power:

- Modifying the frequency control of synchronous generators (e.g., increasing the droop control)

- Limiting the minimum number of online synchronous generators while possibly also decreasing the minimum generation levels at which they can operate (Note: Doing so might impact thermal efficiencies but might nevertheless be cost-effective from a system perspective.)

- Deploying energy storage resources (e.g., battery electricity storage systems)

- Utilizing the potential flexibility of certain loads

- Shedding noncritical loads during specific and nonfrequent conditions (e.g., large solar ramping events, transmission and generation outages, large load and/or solar forecasting errors)

- Implementing frequency control capabilities in the solar PV inverters. One key strategy is to partially curtail solar PV systems to provide enough headroom to provide both downward and upward reserves when called upon.

One fundamental limitation of any inverter-coupled system such as a solar PV power plant is the inability to provide short-circuit contribution at the same levels as synchronous generators. In the case of the Iquitos power system, this could have serious impacts on system protection because of insufficient short-circuit current available for protection activation, especially during periods of high solar generation when larger numbers of synchronous generators will be decommitted. There are several ways to address this issue:

- Oversize the PV and storage inverters in terms of their MVA capability to provide adequate levels of short-circuit current; however, this method is not practical with current prices of power electronic converters. This situation could change in the near future because of rapidly falling prices for power electronics.

- Implement sophisticated communications-based protection systems to provide an adequate level of system protection.

- Add short-circuit current-enhancing devices, such as synchronous condensers.

Many modern energy storage inverters can operate in grid-forming mode. Also, some vendors are currently testing grid-forming PV inverters. The advantage of grid-forming operation is that inverter-coupled generation can mimic all fundamental characteristics of synchronous generators, including rotating inertia, frequency response and regulation, voltage/reactive power control, and fault ride-through performance. In addition, the grid-forming capability makes it possible to use the PV storage system for black-start and system restoration purposes after blackouts. Black-start capability by PV/storage will increase the resilience of the Iquitos power system by adding a "dual-fuel" option to a black start, which is normally performed by diesel generation only. The insufficient overcurrent capability by inverters is still going to be an issue during a black start because of inrush currents required by transformers, transmission lines, and load motors during energizing. A lack of inrush current will cause a voltage collapse during a black start, so this issue needs to be addressed separately in future studies. 


\subsection{Dynamic Simulation Studies}

A detailed study is needed to evaluate the needed upgrades of the Iquitos power system protections to provide adequate levels of fault currents for high $\mathrm{PV} /$ storage penetration scenarios. This will require the development of valid transient models of the Iquitos power system, including models of individual inverters and their control systems provided by vendors. Such models can be used for protection system design and coordination studies, for power quality studies, and for system transient performance and fault ride-though analyses.

For grid operators to estimate the instantaneous PV solar generation that could be reliably integrated into the present Iquitos power system, the following series of dynamic studies are suggested:

- Identify and implement a comprehensive transient simulation model (e.g., in DIgSILENT PowerFactory, or PSCAD) of the PV power plant(s) in the Iquitos power system model.

- Conduct transient simulation studies to determine whether a PV power plant will remain online following a fault (e.g., because of a reactor insulation failure, wildlife, or natural catastrophe).

- Assess whether the dynamic performance of a PV power plant after a fault clears will negatively impact the rotor-angle stability of synchronous machines.

- Evaluate whether anti-islanding protection of a PV power plant will operate as expected in case all synchronous generation disconnects (e.g., as a result of the tripping of a major transmission or distribution line and/or synchronous generator).

- Assess whether the synchronous generation units will be capable of arresting loadgeneration unbalances without violating frequency limits-for example, should a PV power plant disconnect as a result of a severe disturbance (or in case of a fast reduction in solar PV electricity generation because of clouds or during sunset).

- Ascertain the voltage regulation capability of a PV power plant and its cooperativeness with other power plants (e.g., conventional generation units) during normal operation as well as during major transient events.

- Coordinate and adjust protection schemes for the combined operation of inverter-based solar PV power plants and synchronous generators.

These tasks and studies could be conducted for a variety of system design scenarios and system operational conditions. The objective is to predict via simulation whether the system will fail to operate during expected faults and contingencies, e.g., during a transformer failure and disconnection of a generator set. These studies will help identify the instantaneous solar PV penetration levels in the Iquitos power system along with potential power system upgrades and modifications needed to reliably integrate solar PV. 


\section{Conclusions}

In this study for the electrically islanded power system of Iquitos, we presented a time-series analysis to evaluate the impacts of different solar PV generation capacities and PV generation's ability to reduce the use of heavy fuel oil for electricity generation as well as the need to curtail solar energy. This study also assessed the potential of different energy storage capacities to reduce solar curtailment (and therefore increase the amount of heavy fuel oil generation displaced) under different solar PV penetration scenarios.

There is no technical limit to the amount of solar PV that a power system can integrate. Current technologies can be used to operate a system with 100\% solar PV electricity and battery storage. Instead, the limit to solar PV integration is economic in nature, based on how much cost a power system is willing to incur for a desired level of deployment. In some cases, the availability and suitability of land might also be a constraint. In this context, this analysis did not set forth to identify an "optimal" level of solar PV capacity for the Iquitos power system; the optimal design of the power system depends on the goals and constraints of the total system costs and the desired system reliability.

A series of dynamic simulation studies can be performed to evaluate the impact of solar PV generation and batteries on the reliability of the system. These studies can be used to inform cost analyses and unit commitment and economic dispatch models. It is necessary to iterate between the different models and studies to be able to understand and evaluate the trade-off between costs and reliability and to be able to make informed decisions. 


\section{References}

División de Supervisión de Electricidad. 2018. "LÍNEA DE TRANSMISIÓN 220 KV

MOYOBAMBA - IQUITOS (596 km)."

https://www.osinergmin.gob.pe/seccion/centro documental/electricidad/Documentos/PROYECT OS\%20GFE/Acorde $\% \mathrm{C} 3 \% \mathrm{~B} 3 \mathrm{n} /$ Transmisi $\% \mathrm{C} 3 \% \mathrm{~B} 3 \mathrm{n} / 2.2 .2$.pdf

Eke, Rustu, and Thomas R. Betts, and Ralph Gottshalg. 2017. "Spectral Irradiance Effects on the Outdoor Performance of Photovoltaic Modules." Renewable and Sustainable Energy

Reviews 69: 429-434.

ELOR. 2019. Internal workshop during NREL site visit.

Sengupta, Manajit, Yu Xie, Anthony Lopez, Aron Habte, Galen Maclaurin, and James Shelby. 2018. "The National Solar Radiation Data Base (NSRDB)." Renewable and Sustainable Energy Reviews 89: 51-60. 


\section{Appendix A: Solar Energy Resource Detail}

Figure A-1, Figure A-2, and Figure A-3 show how surface air temperature, DNI, and DHI vary across Iquitos during a typical meteorological year (TMY). Surface air temperature is relatively high, and it does not vary significantly throughout the year. The DNI data does not exhibit any observable seasonal patterns. On the other hand, DHI is lowest between May and August, mainly because of the cloud formation during seasonal patterns. Figure A-4 and Figure A-5 show the average daily DNI and DHI profile in Iquitos for each of the 12 months of a TMY. These daily and seasonal patterns affect the diurnal and monthly potential for solar PV electricity generation in Iquitos.

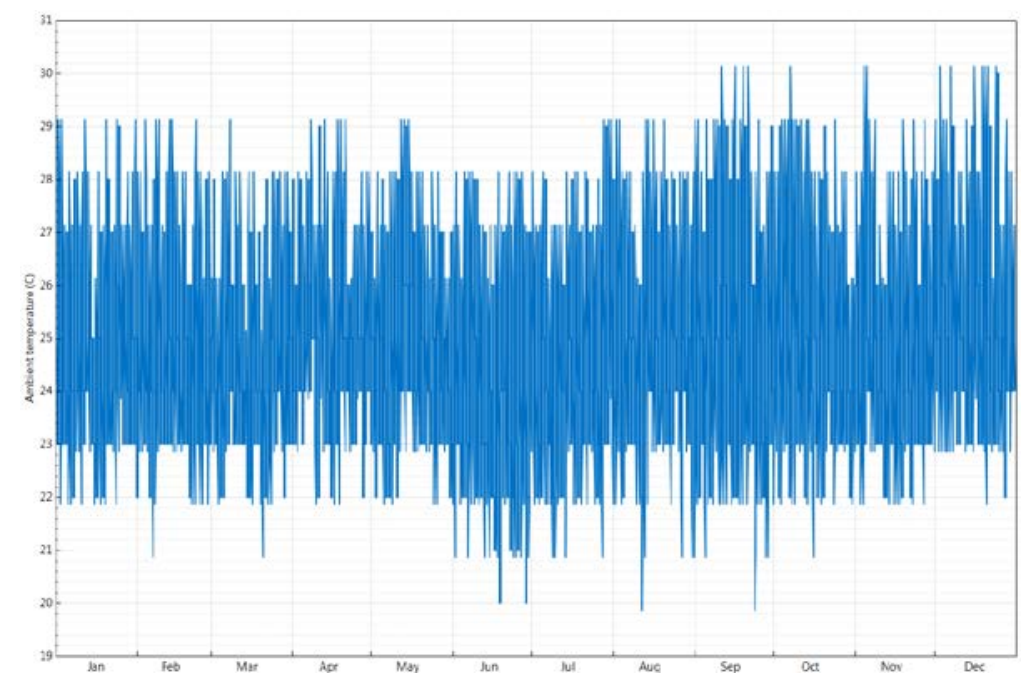

Figure A-1.Surface air temperature: typical meteorological year

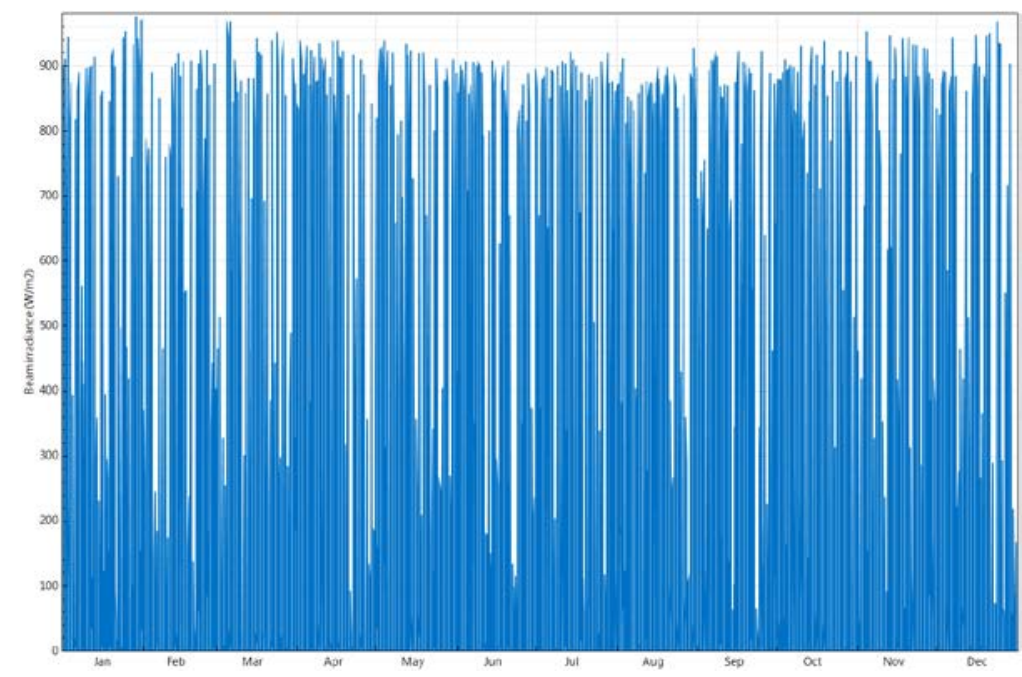

Figure A-2. Direct normal irradiance: typical meteorological year 


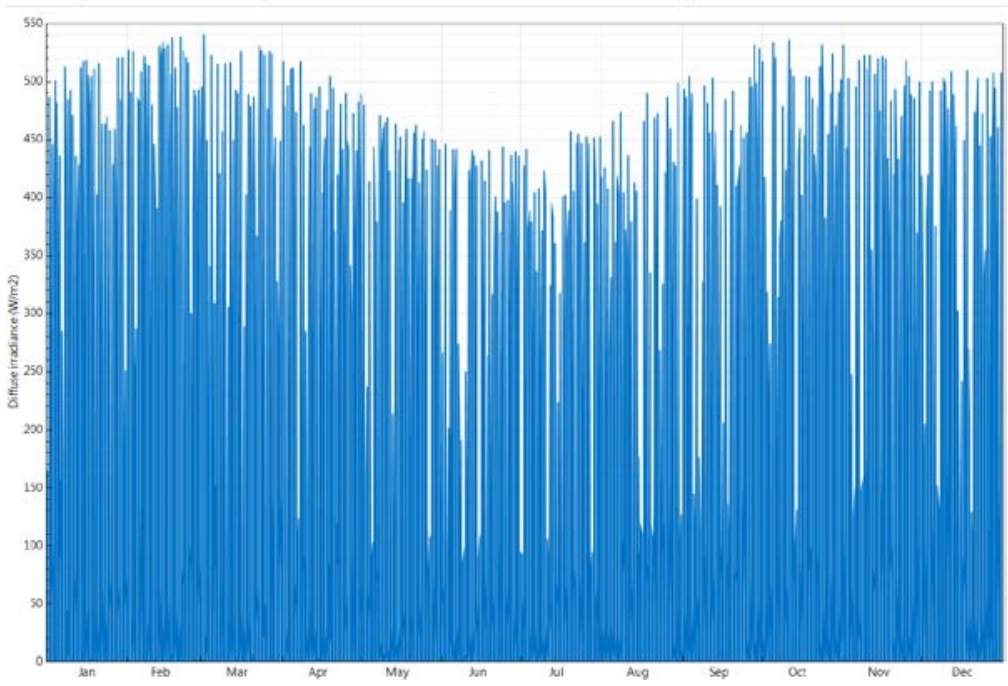

Figure A-3. Diffuse horizontal irradiance: typical meteorological year
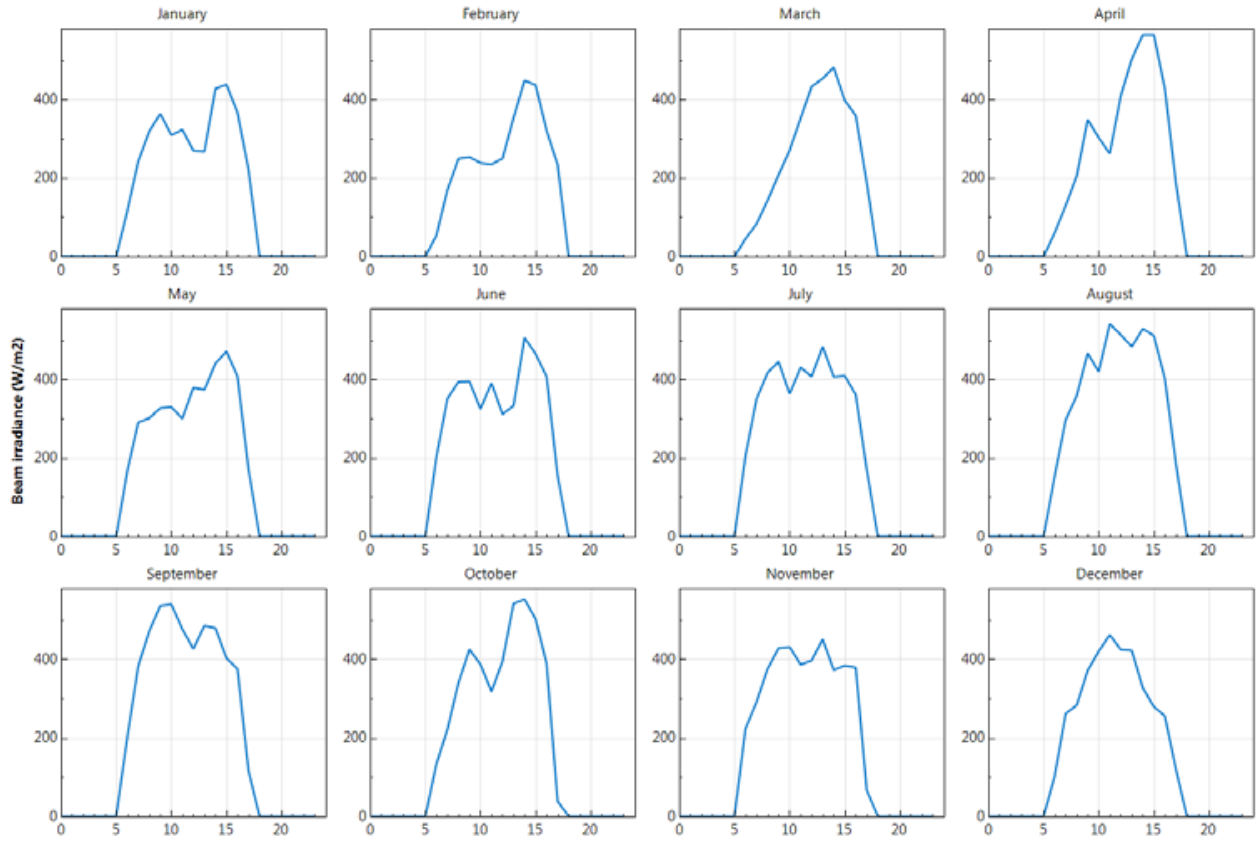

Figure A-4. Direct normal irradiance: daily profile for every month in a typical meteorological year 

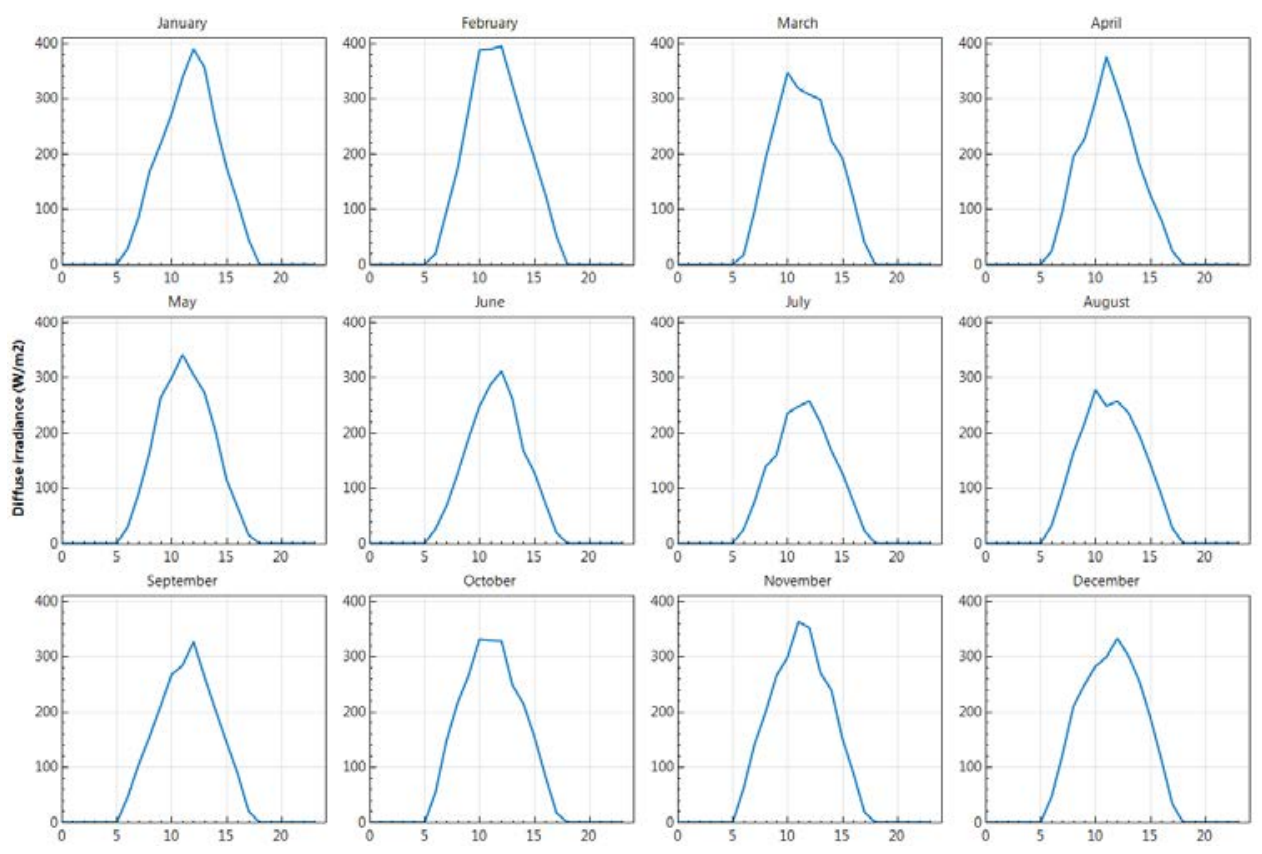

Figure A-5. Diffuse horizontal irradiance: daily profile for every month in a typical meteorological year 


\section{Appendix B: PV System Design Scenarios}

In this section, we analyze the impact of different PV design parameters (array design and module type) on the annual capacity factor in Iquitos. In this sensitivity analysis we assume a 1.0 $\mathrm{DC} / \mathrm{AC}$ ratio to exclude the impacts of the inverter size on annual capacity factors to be able to evaluate the impacts of the two design parameters considered.

We first analyze the net capacity factor for a TMY in Iquitos assuming the following solar PV system design parameters:

- Standard crystalline silicon solar PV modules:

○ $15 \%$ nominal efficiency

- Glass module cover

○ $-0.47 \% /{ }^{\circ} \mathrm{C}$ temperature coefficient of power.

- Orientation horizontal to the ground (0-degree tilt)

- $1.0 \mathrm{DC} / \mathrm{AC}$ ratio (ratio between DC power capacity of solar panels and AC power capacity of inverter)

- $96 \%$ inverter efficiency

- Default SAM system losses: 14.08\% (breakout below)

○ $2 \%$ soiling losses

○ $3 \%$ shading losses

○ $2 \%$ mismatch losses

○ $2 \%$ wiring losses

○ $0.5 \%$ connection losses

○ $1.5 \%$ light-induced degradation losses

○ $1 \%$ nameplate losses

○ $3 \%$ unavailability losses.

We calculate the annual net capacity factor for a TMY for three different array designs:

- Fixed open rack: $14.9 \%$

- Single-axis tracking system: $17.8 \%$

- Dual-axis tracking system: $19.2 \%$

As expected, a single-axis tracking system increases the annual electricity generation potential of the solar PV system design by almost $20 \%$ compared to a fixed-tilt system. A dual-axis tracking system increases it by almost 29\%; however, tracking systems are more capital and operationally expensive, so a trade-off needs to be examined when designing the system.

We also look at the impact of assuming different solar PV system design parameters on the annual net capacity factor. First, we look at the impact of using thin-film solar PV modules (instead of crystalline silicon modules) assuming the following solar PV system design parameters: 
- Thin-film solar PV modules:
○ $10 \%$ nominal efficiency
- Glass module cover
○ $-0.20 \% /{ }^{\circ} \mathrm{C}$ temperature coefficient of power.

The annual net capacity factor for a TMY increases for the three different array designs:

- Fixed open rack: $16.1 \%$

- Single-axis tracking system: $19.4 \%$

- Dual-axis tracking system: $21.1 \%$.

Thin-film modules generate more electricity than standard crystalline silicon modules in Iquitos mainly because of the relatively high air temperature throughout the year. Thin-film modules have a lower temperature coefficient of power. Also, the overall cloud cover might impact the incoming light wavelength that is beneficial for thin-film modules (blue shift). ${ }^{6}$ Currently, thinfilm solar modules are considered to have very similar lifetime and system cost per installed capacity to crystalline silicon modules. The major difference between the two solar module types is efficiency and, therefore, land use. Other differences will vary among specific modules from different commercial vendors.

\footnotetext{
${ }^{6}$ Regions with high humidity (e.g., Florida) can remove parts of the infrared spectrum that c-Si modules absorb that thin-film $(\mathrm{CdTe})$ modules do not, resulting in effectively higher power generation in these regions for a thin film system with the same nameplate wattage as a c-Si system (Eke, Betts, Betts, and Gottshalg 2017).
} 


\section{Appendix C: Inverter Sizing Discussion}

A solar PV system design parameter that has a significant impact on the project capital cost and on the annual electricity generation potential is the ratio between the DC power capacity of the solar panels to the $\mathrm{AC}$ power capacity of the inverter (referred to as the $\mathrm{DC} / \mathrm{AC}$ ratio). $\mathrm{PV}$ produces in DC but needs to send out power to the grid in AC through an inverter. This ratio is usually higher than 1.0 because in practice solar modules never generate their full DC rated capacity due to suboptimal conditions, unavailability of some modules, and system losses. Solar PV plant developers can reduce the cost of the project by downsizing the capacity of the inverter while barely affecting the annual generation potential. In some solar PV power plants around the world, the $\mathrm{DC} / \mathrm{AC}$ ratio can be much higher than 1.0, reaching values of 1.5 or higher. In power systems with very high penetrations of solar power, higher DC/AC ratios might be justified by the fact that solar PV plants are often curtailed when generating close to their rated capacity, and therefore reducing the inverter size does not have a large impact on the annual generation potential that would be injected in the system. This however would be different in a scenario with energy storage that could store the excess energy that would otherwise be curtailed.

Table A-1 shows the impact that the DC/AC ratio has on the annual net capacity factor (both in terms of the DC capacity of the modules and the AC capacity of the inverter) of a solar PV system in Iquitos with thin-film modules for a fixed open rack system. CF-DC stands for the annual average net capacity factor for a typical meteorological year (TMY) as a function of the DC capacity of the solar panels. On the other hand, CF-AC stands for the annual average net capacity factor for a TMY as a function of the AC capacity of the inverter. Each row represents the same amount of PV panels (or in other words, the same DC capacity). As the DC/AC ratio increases, the PV panels remain the same, but the size of the inverter decreases. Therefore, the capacity factor (or energy generated in average) decreases in terms of DC capacity as the energy output is limited by the inverter capacity.

On the other hand, the capacity factor (or energy generated in average) increases in terms of AC capacity as the size of the inverter is reduced. The difference between the two values is a measure of the energy that could potentially be injected in the power system by the solar PV plant but is not available due to inverter capacity and characteristics.

Table A-1. DC/AC Ratio Impact on Net Capacity Factor

(Fixed Open-Rack System)

\begin{tabular}{lll}
\hline DCIAC & $\begin{array}{l}\text { CF-DC } \\
(\%)\end{array}$ & $\begin{array}{l}\text { CF-AC } \\
(\%)\end{array}$ \\
\hline 1.0 & 16.1 & 16.1 \\
1.2 & 16.1 & 19.3 \\
1.4 & 16.1 & 22.5 \\
1.6 & 15.7 & 25.1 \\
1.8 & 15.2 & 27.4 \\
2.0 & 14.6 & 29.2 \\
\hline
\end{tabular}


In a fixed open-rack system, reducing the power capacity of the inverter by $29 \%(\mathrm{DC} / \mathrm{AC}=1.4)$ has almost no effect on the potential annual electricity generated by the solar PV system and injected into the grid. If the inverter capacity is reduced by half $(\mathrm{DC} / \mathrm{AC}=2.0)$, the potential annual electricity generation is reduced by $9 \%{ }^{7}$. The DC/AC ratio of the solar PV system also impacts the profile of the electricity generated by the solar PV system and injected in the grid. Figure A-6 shows the average daily profile of the electricity generation of a solar PV system with an inverter power capacity of $1 \mathrm{MW}$ for different $\mathrm{DC} / \mathrm{AC}$ ratios.

Increasing the $\mathrm{DC} / \mathrm{AC}$ ratio (i.e., reducing inverter size) can lower upfront capital costs, allow the system to respond to variable changes in solar resource, and allow for the system to respond faster. However, a higher DC/AC ratio for the same inverter capacity will lead to higher costs to build more solar modules and use more land. The trade-offs of choosing DC/AC ratio must be examined upfront to reduce system costs (inverter pricing scales with capacity) and to optimize system performance and ramping.

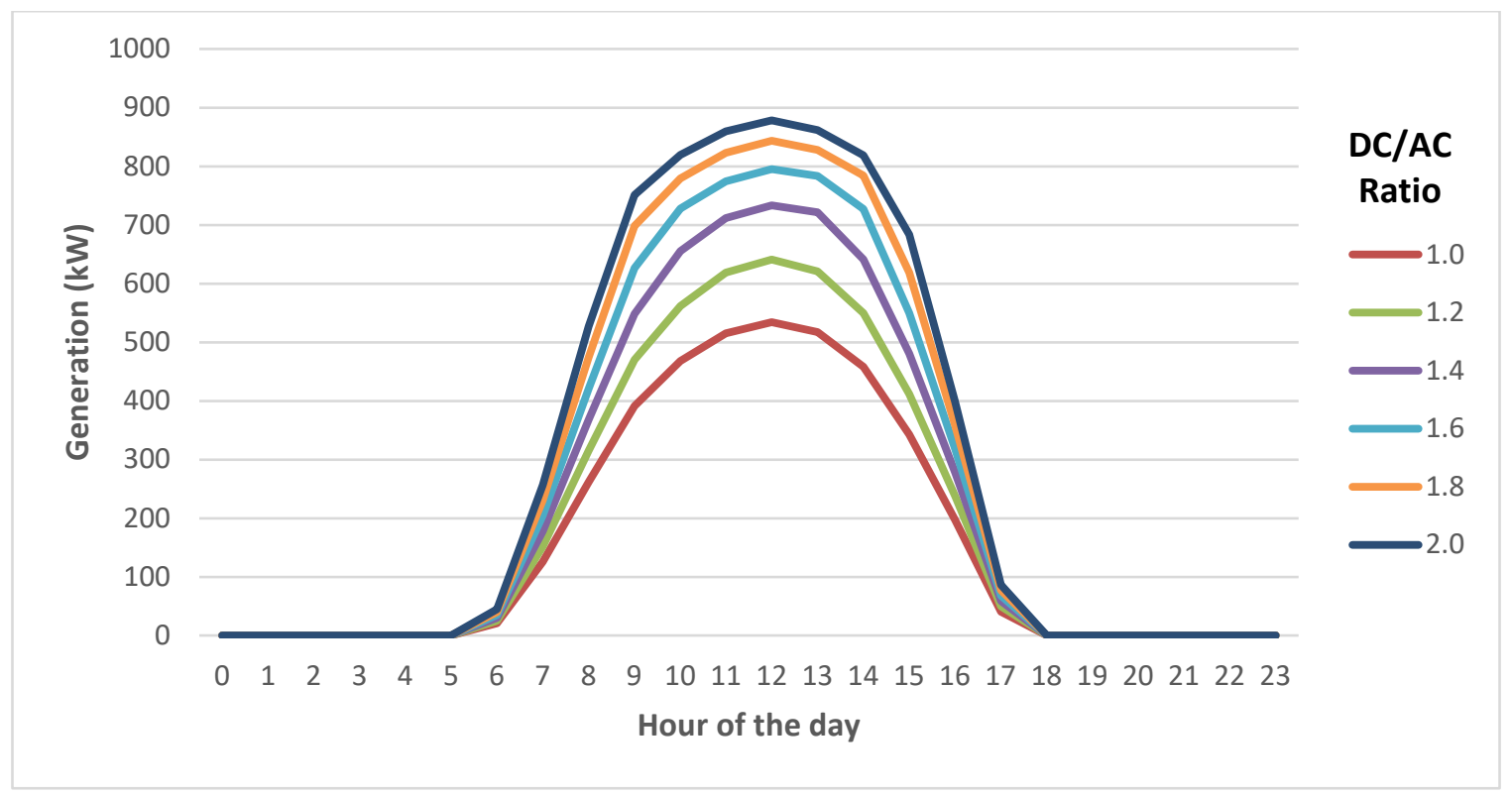

Figure A-6. DC/AC ratio impact on average daily solar PV electricity generation profile

\footnotetext{
${ }^{7}$ For a lower DC/AC ratio, the amount of energy potential that is "clipped" (or, in other words, curtailed due to the installed power capacity of the inverter) is very small or negligible. With higher DC/AC ratios (e.g., 2.0), the amount of energy that gets clipped increases (in this case, up to a total of $9 \%$ ).
} 